\title{
Switching azonaphthols containing a side chain with limited flexibility. Part 1. Synthesis and tautomeric properties
}

\author{
Vanya B. Kurteva ${ }^{\mathrm{a}, *}$, Liudmil M. Antonov ${ }^{\mathrm{a}, *}$, Daniela V. Nedeltcheva ${ }^{\mathrm{a}}$, Aurélien Crochet ${ }^{\mathrm{b}}$, \\ Katharina M. Fromm ${ }^{b}$, Rositsa P. Nikolova ${ }^{c}$, Boris L. Shivachev ${ }^{c}$, Maya S. Nikiforova ${ }^{a}$ \\ ${ }^{a}$ Institute of Organic Chemistry with Centre of Phytochemistry, Bulgarian Academy of Sciences, Acad. G. Bonchev str., bl. 9, 1113 Sofia, Bulgaria \\ ${ }^{\mathrm{b}}$ University of Fribourg, Department of Chemistry, Chemin du Musée 9, CH-1700 Fribourg, Switzerland \\ 'Institute of Mineralogy and Crystallography "Acad. Ivan Kostov", Bulgarian Academy of Sciences, Acad. G. Bonchev str., bl. 107, 1113 Sofia, Bulgaria
}

\begin{abstract}
A series of azo dyes, possessing amide fragments with restricted flexibility tethered to 4-(phenyldiazenyl)naphthalen-1-ol, was obtained from 1-hydroxy-2-naphthoic acid by subsequent conversion to amides and diazo coupling. It was shown that the position of the tautomeric equilibrium in solution strongly depends on the solvent in both UV and NMR concentration scale. The compounds exist as pure enol forms in chloroform and hydrocarbons, while in polar solvents (acetone, acetonitrile, alcohols) a tautomeric mixture is observed. According to the quantum-chemical calculations the aggregation of the keto tautomer is the possible reason for this shift in the position of the tautomeric equilibrium. To support the theoretical predictions, it was found that from acetone the keto form crystallizes as a dimer with hydrogen bonding between $\mathrm{N}_{1}-H$ in the one molecule and amide $\mathrm{C}=\mathrm{O}$ in the other forming a three-dimensional structure. The importance of the side-chain nitrogen atom on the dimer formation was confirmed by solution and solid state study of 4-(phenyldiazenyl)-2-acetylnaphthalen-1-ol. The results indicate that the new azo-dyes obtained could be suitable candidates for switching and sensing applications in non-polar solvents.
\end{abstract}

\section{Introduction}

The design of selective and sensitive chemosensors for ions and systems for molecular recognition has developed at the extraordinary rate due to their potential application in clinical biochemistry, analytical chemistry and environmental science [1-9]. Organic chemosensors are molecules of abiotic nature capable of interacting selectively with a specific substrate accompanied with corresponding changes in one or more characteristics of the system, i.e. to detect certain chemical stimuli in the environment.

Azo compounds are among the most widely examined coloring and signaling systems due to their optical stability [10-17]. However, when both tautomeric forms coexist in solution at room temperature the isolation of individual end-structures represents a general problem, which limits their use for sensing purposes. Recently, the concept for a tautomeric switch, where a directed

\footnotetext{
* Corresponding authors. Tel.: +359 2 9606156; fax: +359 28700225.

E-mail addresses: vkurteva@orgchm.bas.bg (V.B. Kurteva), lantonov@orgchm. bas.bg (L.M. Antonov)
}

shift in the position of the tautomeric equilibrium can be achieved through protonation and/or complexation, was proven by attaching of a flexible nitrogen linked piperidine [18] (1, Fig. 1) or 1-aza15-crown-5 [19] (2) fragment to 4-(phenyldiazenyl)naphthalen-1ol. Both compounds were isolated as pure enol forms due to strong hydrogen bonding between tautomeric hydroxyl group and the side chain nitrogen atom and were fully converted to ketotautomers, which, to the best of our knowledge, present the first examples of an active side-arm containing chemosensors with significant bathochromic and hyperchromic effects of the absorption maximum upon protonation or complexation. The developed tautomeric aza-15-crown-5 system 2 has shown acceptable complexation with small alkali and alkaline earth metal ions. However, the selectivity toward different metals was relatively low, most probably due to flexibility of the methylene spacer and the azacrown moiety. In order to restrict the rotation of the side chain the methylene group was replaced with carbonyl function, capable of forming a strong hydrogen bond with the tautomeric hydroxyl. Additionally this could lead to reduction of the electron density at the heterocycle nitrogen atom as a tuning tool to model the complexation ability of the attached heterocycle. 


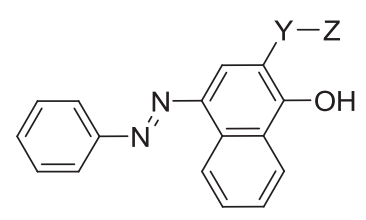

$$
\begin{aligned}
& 1 \mathrm{Y}=\mathrm{CH}_{2} ; \mathrm{Z}=\text { piperidine } \\
& 2 \mathrm{Y}=\mathrm{CH}_{2} ; \mathrm{Z}=\text { aza-15-crown-5 } \\
& 3 \mathrm{Y}=\mathrm{C}=\mathrm{O} ; \mathrm{Z}=\mathrm{N} \text {-heterocycle } \\
& 4 \mathrm{Y}=\mathrm{C}=\mathrm{O} ; \mathrm{Z}=\mathrm{CH}_{3}
\end{aligned}
$$

Fig. 1. Azonaphthol dyes.

Herein, we present the synthesis of a series of azo dyes (3) possessing amide fragments tethered to 4-(phenyldiazenyl)naphthalen-1-ol and a study on their conformational preferences and tautomeric properties in the gas phase, solutions and in the solid state. As a comparison, the spectral data of compound $\mathbf{4}$, where the nitrogen containing heterocycle is absent, will be considered.

\section{Results and discussion}

The target azo dyes $\mathbf{3}$ were obtained from 1-hydroxy-2naphthoic acid $\mathbf{5}$ by subsequent conversion to amides $\mathbf{6}$ and diazo coupling as a one-pot two step protocol without intermediate purification, as shown on Scheme 1. Piperidine (a), morpholine (b), and $\mathrm{N}$-phenylpiperazine (c) were chosen as $\mathrm{N}$-heterocyclic units in order to examine the influence of the presence and the type of the additional heteroatoms on the position of the tautomeric equilibrium.

As a first step, the conditions for the preparation of the amides $\mathbf{6}$, which was expected to be attended with synthetic problems due to the presence of the reactive phenolic hydroxyl group in the acid molecule, were optimized using the piperidino derivative by checking different approaches. The direct amide coupling in the presence of $N$-(3-dimethylaminopropyl)- $N^{\prime}$-ethylcarbodiimide hydrochloride (EDCI) and 1-hydroxybenzotriazole (HOBT) led to a side product 8a formation with the participation of the hydroxyl group (Scheme 2). Its structure was assigned by 1D and 2D NMR spectroscopy, where characteristic ester and amide resonances were observed.

The classical protocol for the preparation of the amides via acyl chlorides, heating of the acid in thionyl chloride followed by reaction with piperidine, resulted in a very complex mixture. The amide 6a was isolated in low yield after several subsequent chromatography purifications, along with some side-products, the chlorinated compound 7a and the already obtained ester-amide 8a. The formation of these side products, which could be achieved only during the preparation of the acid chloride, showed that the harsh classical conditions are not efficient in this case. The chlorination was further performed in solution with 4-fold excess of thionyl chloride by following the protocol applied in the synthesis of similar compounds [20] and the target amide $\mathbf{6 a}$ was isolated in good yield together with slight impurity of $\mathbf{8 a}$. The same result was obtained for $\mathbf{6 b}$. Finally, the excess of the reagent was reduced and the amides $\mathbf{6 a}-\mathbf{6 c}$ were obtained as sole products and were directly used in the next step. Diazo coupling was carried out via a standard protocol (Scheme 1) and the pure products 3 were isolated by high performance flash chromatography on silica gel in good overall yields.

The position of the tautomeric equilibrium in $\mathbf{3}$ was studied by quantum-chemical calculations and mass spectrometry in the gas phase and was afterward investigated by NMR and UV spectroscopy in solution and by X-ray in the solid state.

It was reported in the case of $\mathbf{1}$ [18] that the intramolecular hydrogen bonding between the piperidine nitrogen atom and the enol $\mathrm{OH}$ group leads to full shift of the equilibrium towards the enol tautomer in chloroform, cyclohexane, acetone and acetonitrile. This bonding is probably partially broken in the case of alcohols, where an enol predominating tautomeric mixture is observed. The absorption spectra of 3a, shown in Fig. 2 show a different behavior. The tautomeric equilibrium is switched to the enol isomer (absorption maximum at $400 \mathrm{~nm}$ ) only in chloroform and cyclohexane and increasing amount of the keto tautomer is observed in acetone, acetonitrile and ethanol. The increase of the concentration in acetonitrile and in acetone from $10^{-5}$ to $10^{-3} \mathrm{~mol} / \mathrm{l}$ leads to slight rise of the keto band at $470 \mathrm{~nm}$ suggesting an aggregation effect, while in the case of the chloroform no spectral changes were observed.

The quantum-chemical calculations performed (Fig. 3) show that the enol form (E) can exist as two isomers depending on the hydrogen bonding formation. Logically the side chain $\mathrm{C}=\mathrm{O}$...HO interaction is preferred, but both isomers are substantially more stable in comparison to the keto tautomer $(\mathrm{K})$ in the gas phase. On the other side the side chain of the keto form is out of planarity, which gives possibility for intermolecular interaction $(\mathrm{N}-\mathrm{H} \ldots \mathrm{O}=\mathrm{C}$ side chain) with another molecule and to formation of a dimer $\left(D_{K}\right)$, which leads to final stabilization of appr. $2 \mathrm{kcal} / \mathrm{mol}$ in respect of the more stable enol form (Fig. 3a).

The overall process can be summarized as follows:

$\mathrm{E} \rightleftarrows \mathrm{K} \rightleftarrows \mathrm{D}_{\mathrm{K}}$

In gas phase the tautomeric equilibrium is shifted to the enol isomer, but in solution the situation could be determined by the polarity and/or proton-acceptor/donor ability of the solvent. At the same time, the dimer formation requires availability of the keto tautomer. According to the quantum-chemical calculations the keto tautomer is slightly more polar (3.5D against 3.1D for the enol form) and it is the form that gives better opportunities for interaction with proton-acceptor solvents (free $\mathrm{N}-\mathrm{H}$ ). In chloroform, a bulky, strong proton-donor and low polar solvent, there are no

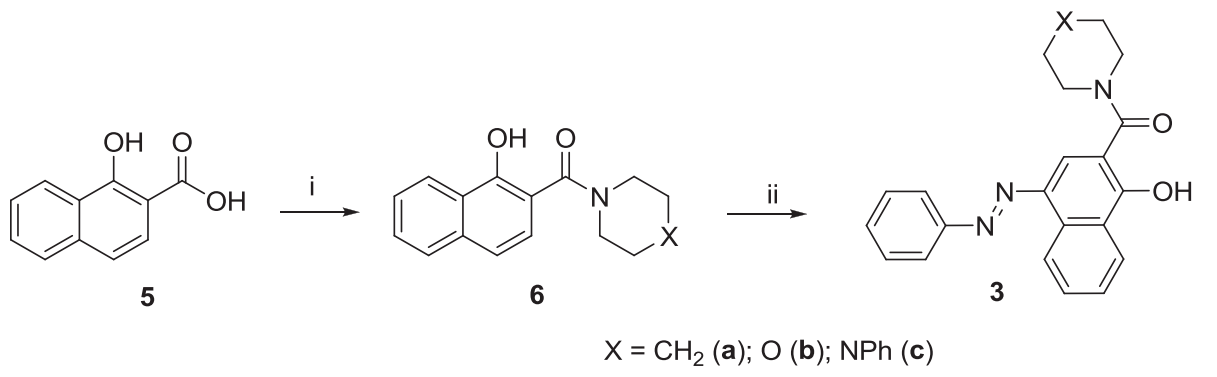

Scheme 1. 1) see Scheme 2; ii) $\mathrm{PhNH}_{2}$, conc. $\mathrm{HCl}, \mathrm{NaNO}_{2}$, acetone- $\mathrm{H}_{2} \mathrm{O}, \mathrm{NaOH}$. 


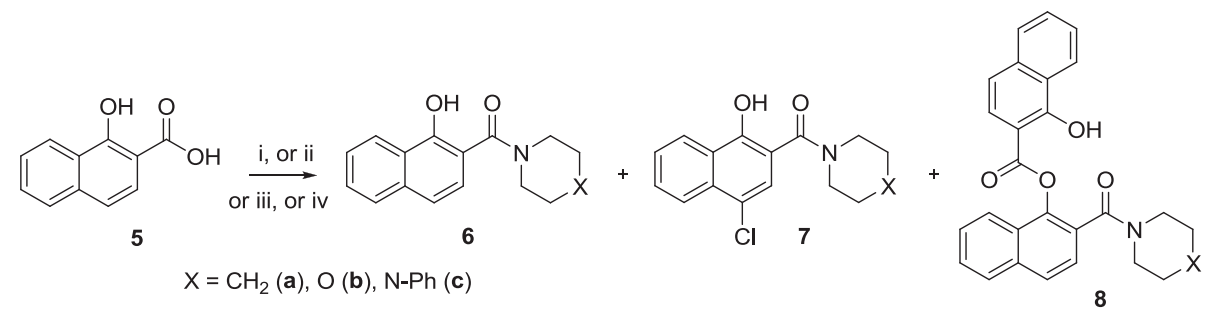

Scheme 2. i) piperidine, $\mathrm{EDCl}, \mathrm{HOBT}, \mathrm{CH}_{2} \mathrm{Cl}_{2}$, rt; ii) 1 . $\mathrm{SOCl}_{2}$, reflux; 2. piperidine, $\mathrm{CH}_{2} \mathrm{Cl}_{2}$, rt; iii) $\mathrm{SOCl}_{2}$ (4 equiv), DMF, heptane, reflux, 4 h; 2 . piperidine or morpholine, $i-\mathrm{Pr}_{2} \mathrm{NEt}$, $\mathrm{CH}_{2} \mathrm{Cl}_{2}$, rt; iv): 1 . $\mathrm{SOCl}_{2}$ (2.5 equiv), DMF, heptane, reflux, $4 \mathrm{~h}$; 2. piperidine or morpholine, $i-\mathrm{Pr}_{2} \mathrm{NEt} \mathrm{CH}_{2} \mathrm{Cl}_{2}$, rt.

possibilities to shift the equilibrium to the more polar keto form, in which $\mathrm{C}=\mathrm{O}$ group is sterically hindered for hydrogen bonding with the solvent. However, in acetonitrile and in acetone (due their higher polarity and substantial proton-acceptor abilities [21]) a proportion of the keto tautomers are available giving the background for dimer formation.

As seen from Fig. 3a, the energies of the structures in acetonitrile field (PCM calculations) suggest substantial stabilization of the keto tautomer in respect of the enol forms (relative energy lows from 4.1 to $0.8 \mathrm{kcal} / \mathrm{mol}$ and from 8.1 to $3.4 \mathrm{kcal} / \mathrm{mol}$ ) and the dimeric structure remains most stable at the same time. The interactions of the tautomers with acetone (Fig. 3b) dramatically change the situation leading to comparably stable keto monomer, keto dimer and $\mathrm{C}=\mathrm{O} \ldots \mathrm{HO}$ enol form. The leading force is the intermolecular hydrogen bonding between the tautomeric proton and the acetone $\mathrm{C}=\mathrm{O}$ group.

The mass spectra of $\mathbf{3}$ not only confirm the existence of the enol tautomer in gas phase [21], but give indications for co-existence of the $\mathrm{C}=\mathrm{O} \ldots \mathrm{HO}$ and $\mathrm{N}$...HO isomers. While in the case of $\mathbf{1}$ the fragmentation begins with loss of piperidine [22], in $\mathbf{3 a}$ (Scheme 3 as a representative example for $\mathbf{3}$ ) this fragmentation pathway (appearance of $m / z 274$ and subsequent fragmentation) is accompanied by cleavage of the $=\mathrm{N}-\mathrm{C}_{\text {naph }}$ bond $(\mathrm{m} / \mathrm{z} 254$ and $\mathrm{m} / \mathrm{z}$ 105),

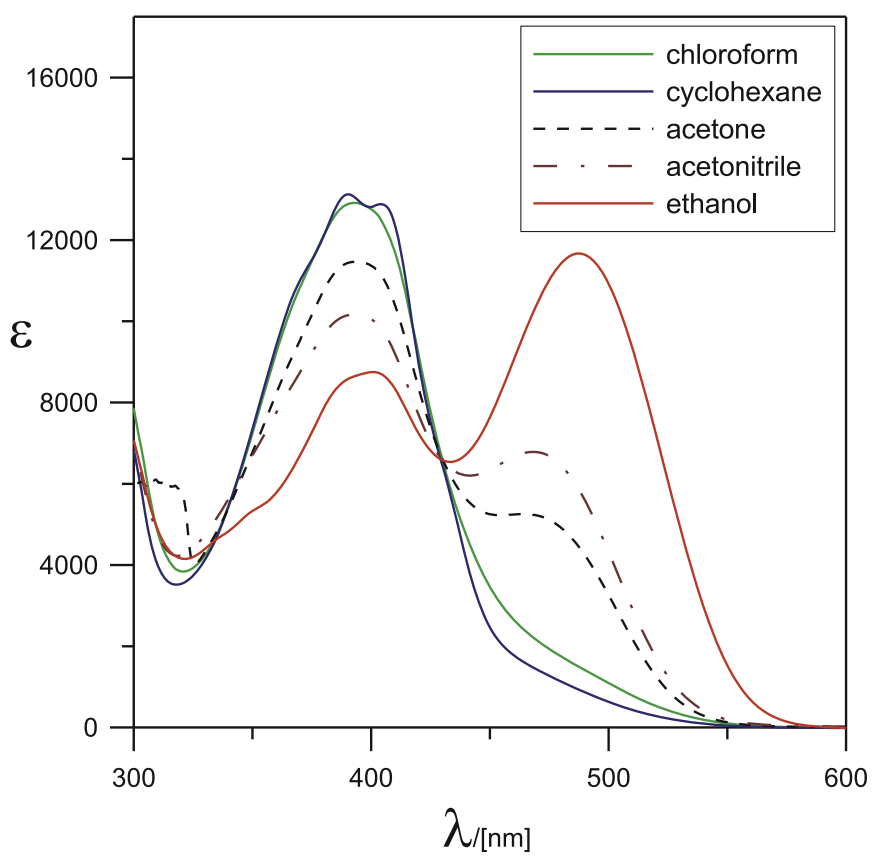

Fig. 2. Absorption spectra of $\mathbf{3 a}$ in various solvents. which results from the $\mathrm{C}=\mathrm{O}$...HO interaction hindering migration of the tautomeric proton towards the piperidine unit. The mass spectrum from methanol- $\mathrm{d}_{4}$ solution additionally shows that both isomers of the enol tautomer coexist in gas phase, because the molecular ion radical $(\mathrm{m} / \mathrm{z} 360$ ) again gives fragment $\mathrm{m} / \mathrm{z} 274$ (loss of deuterated piperidine, which requires intramolecular hydrogen bonding involving the piperidine nitrogen atom [21]) along with fragment with $m / z 255$.

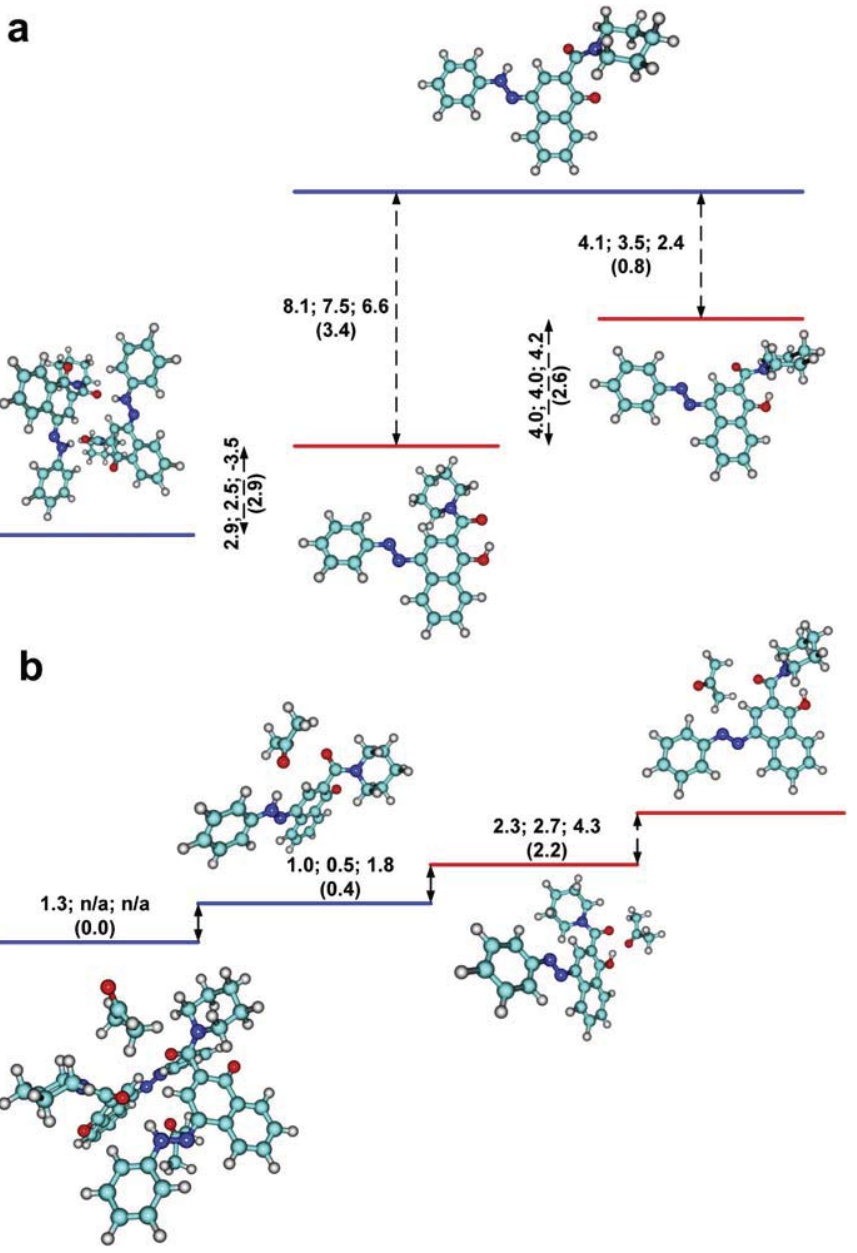

Fig. 3. The values of the relative energy $\left(\mathrm{HF} / 6-31 \mathrm{G}^{* *}\right)$, relative energy $+\mathrm{ZPE}$ correction and $\Delta \Delta G(\mathrm{kcal} / \mathrm{mol})$ of the tautomers of 3a: a) in gas phase; the relative energies in acetonitrile environment are given in brackets; b) with addition of a molecule acetone; the relative energies in acetone environment are given in brackets. 


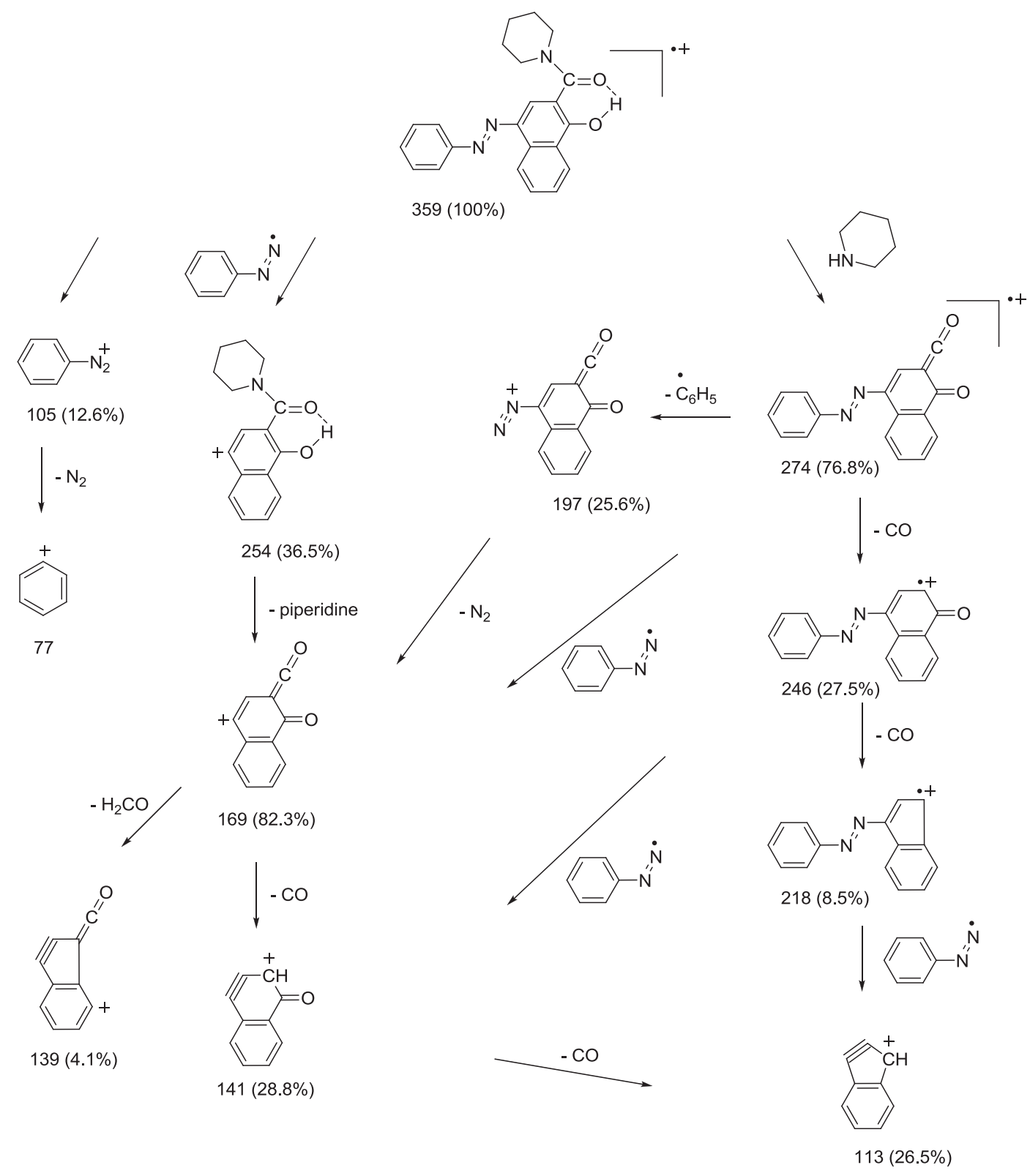

Scheme 3. Fragmentation of 3a

The NMR spectra of the products in $10^{-1} \mathrm{M}$ concentration in deuterochloroform showed sharp and well defined signals consistent with enol forms. It can be suggested that azo dyes $\mathbf{3}$ exist in chloroform as single enol form, as was observed for analogues with flexible side-chain $\mathbf{1}$ [18] and $\mathbf{2}$ [19], and contrary to unsubstituted 4-phenylazo-1-napthol and 2-phenylazo-1-napthol, where both tautomers coexist and the populations of the keto forms are calculated from ${ }^{13} \mathrm{C}$ and ${ }^{15} \mathrm{~N}$ spectra $[23,24]$. The preferred conformations of amide side chains (Fig. 4) were studied by ${ }^{1} \mathrm{H}-{ }^{1} \mathrm{H}$ NOESY experiments. Strong interactions of the singlet for $\mathrm{CH}-3$ with the ring methylene groups were observed in all spectra, while no $\mathrm{CH}_{2} \ldots \mathrm{OH}$ interactions were detected, which are compatible with conformers 3B.

The results in chloroform were in full agreement with the UV-Vis data in respect of the enol stabilization. In order to study if the influence of the solvent on the position of the tautomeric equilibrium is dependent on the concentration, the NMR spectra of the products $\mathbf{3 a}-\mathbf{3 c}$ were recorded in $10^{-1} \mathrm{M}$ solutions in deuteroacetone. The proton spectra showed broad signals and the hydroxyl group resonances were not detected, which is consistent with slow exchange between two sites. The latter was supported by the fact that the complete carbon spectra were not detected within a reasonable time-scale. The spectra of a selected sample (3b) in deuteroacetone were recorded at low temperature (213 K) at $5 \times 10^{-2} \mathrm{M}$ concentration in order to avoid the product crystallization (crystal formation was observed at $278 \mathrm{~K}$ in $10^{-1} \mathrm{M}$ solution) and clear signals for both exchangeable forms were detected. The assignment of the signals was achieved by 2D techniques. The HMBC cross peaks explicitly show that the carbonyl resonances at $180.6,169.4,165.9$, and 158.0 belong to $C=$ $\mathrm{O}, \mathrm{K}, \mathrm{NC}=\mathrm{O}, \mathrm{E}, \mathrm{NC}=\mathrm{O}, \mathrm{K}$, and $\mathrm{C}_{\mathrm{q}}-\mathrm{OH}$, respectively. The double signals observed for a part of the $\mathrm{E}$ carbons at $213 \mathrm{~K}$ is most probably due to 3A-3B (Figure 4) slow exchange, as both forms differ significantly in relative energy due to strong $\mathrm{H}$-bond in $\mathbf{3 B}$. 

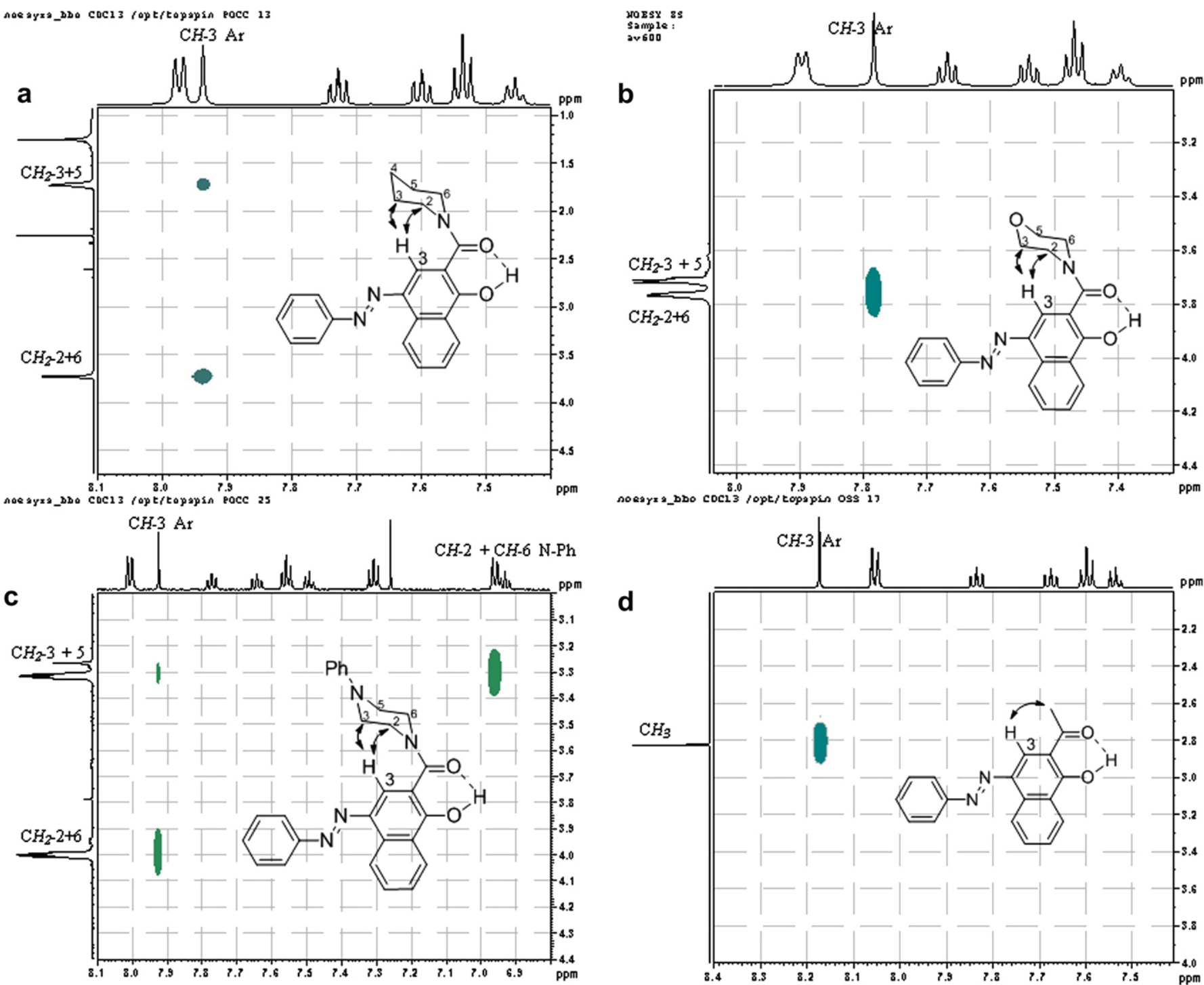

Fig. 4. Conformations of the amide side chain in $\mathbf{3}$ and important ${ }^{1} \mathrm{H}-{ }^{1} \mathrm{H}$ NOESY interactions in: a) 3a; b) $3 \mathbf{b}$; c) $3 \mathbf{c}$; d) 4 .

The spectra of $\mathbf{3 b}$ were additionally compared with the spectra in deuteroacetone of already published [25] O-methyl and $N$-methyl derivatives of 4-phenylazo-1-naphthol, model enol and keto analogues, respectively. The carbonyl resonances of $\mathbf{3 b}$ are in full accordance with those of the model compounds, as illustrated on Fig. 5. So, it can be suggested that the exchange observed in $\mathbf{3}$ is due to keto-enol equilibrium. These results show that the tautomeric preferences are strongly dependent on the solvent both in UV and in NMR concentration scales.

The crystals of $\mathbf{3 b}$ were obtained by slow diffusion of hexane into acetone solution of the product. Unfortunately, all other solvent systems used led to small crystal formation and X-ray analyses were not successful. It was found that the product crystallize in keto form as a dimer with tautomeric proton "delocalized" between $N_{1}-H$ in the one molecule and amide $\mathrm{C}=\mathrm{O}$ in the other (Fig. 6) thus forming an interesting three-dimensional structure (Fig. 7), where a molecule of acetone is captured [26]. This result strongly supports the suggestions made on the base of the quantum-chemical calculations for 3a and the observed spectral properties in acetone.

To ascertain the influence of the side chain heteroatoms on the conformational preferences of the products, the simplified analogue of 3 possessing methyl group instead of $\mathrm{N}$-heterocycle was chosen as useful candidate. Thereby, 4-phenylazo-2-acetyl-1naphthol 4 was obtained from commercially available 2-acetyl-1naphthol 9 by diazo coupling (Scheme 4).

The NMR spectra of $\mathbf{4}$ showed sharp signals compatible with individual form, i.e. with absence of exchange. From the other side, the NOESY interaction between $\mathrm{CH}-3$ and $\mathrm{CH}_{3}$-group (Fig. 4d) shows that in chloroform solution at room temperature the product exists as $\mathbf{4 B}$ form. The spectra in deuteroacetone with the same concentration $\left(10^{-1} \mathrm{M}\right)$ showed again sharp signals compatible with enol tautomer, which indicates that the side-chain nitrogen in 3 has significant influence on the conformational preferences of the azo dyes.

The UV spectral data in various solvents show that in all cases the equilibrium is shifted to the enol tautomer. These results are supported by the quantum-chemical calculations shown in Fig. 8. The enol form is strongly stabilized through intramolecular hydrogen bonding, where the tautomeric proton is "delocalized" between the carbonyl groups. The crystal structure of $\mathbf{4}$ [26] (Fig. 9) supports the calculations and spectral results, showing the existence of the enol tautomer, stabilized through strong $\mathrm{C}=\mathrm{O} \ldots \mathrm{H}-\mathrm{O}$ 

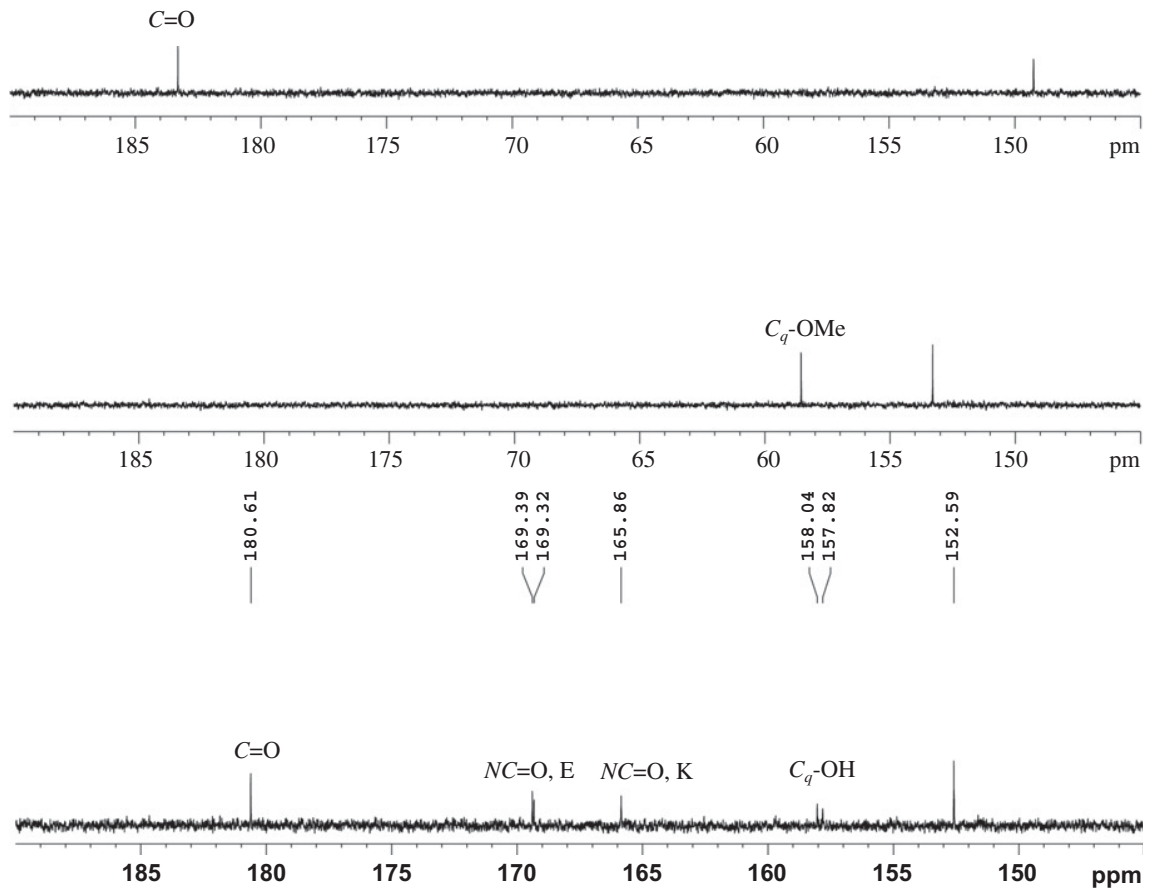

Fig. 5. Carbonyl area of ${ }^{13} \mathrm{C}$ NMR spectra in deuteroacetone of $3 \mathbf{b}$ at $213 \mathrm{~K}$ (down) and 0 -methyl (middle) and $N$-methyl (up) derivatives of 4-phenylazo-1-naphthol at $298 \mathrm{~K}$.

bonding (according to Gilli et al. [27] in the light of the bond distances of $0.820 \AA$ for the $\mathrm{O}-\mathrm{H}$ bond and $1.816 \AA$ for $\mathrm{H} \ldots \mathrm{O}=\mathrm{C}$ bond). This hydrogen bonding is much stronger that the $\mathrm{N}$...H-O interaction in $\mathbf{1}$ [18], which leads the better stabilization of the enol tautomer (9.8 vs $4.2 \mathrm{kcal} / \mathrm{mol}$ ).

According to the theoretical calculations, the keto tautomer is essentially planar and the formation of dimers, although stabilize the keto form by itself, do not lead to stabilization in respect of the enol tautomers.

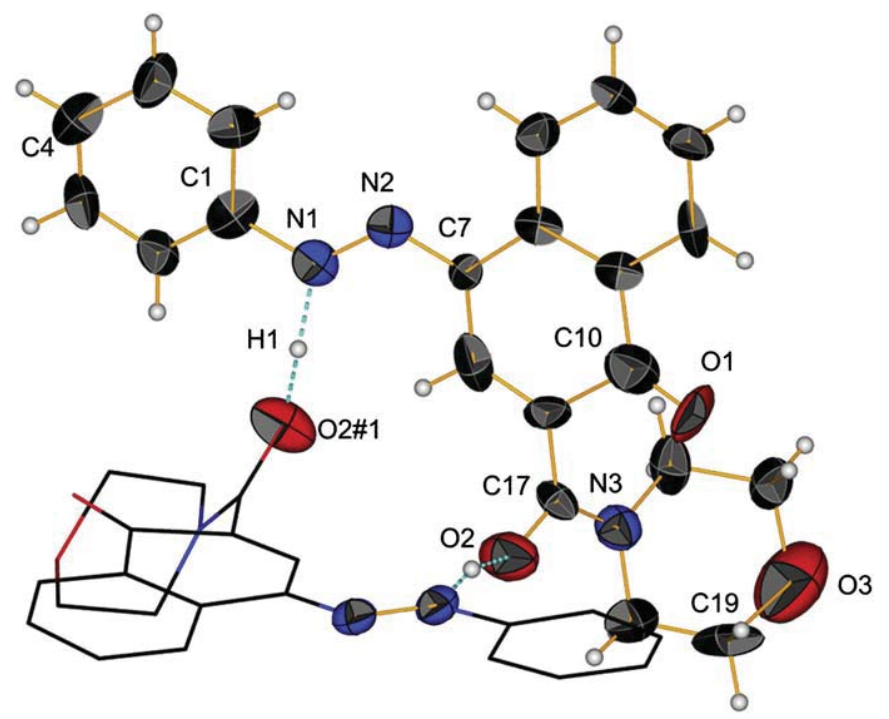

Fig. 6. View of molecular structure of $3 \mathrm{~b}, 50 \%$ of probability, H-bond are drawn in dashed blue, solvent molecules and some hydrogen atoms are omitted for clarity, \#1: $1-x, y, 0.5-z$. (For interpretation of the references to colour in this figure legend, the reader is referred to the web version of this article.)

\section{Conclusions}

We report herein on the synthesis, tautomeric properties and conformational preferences of switching azonaphthols containing a side chain with limited flexibility. The target azo dyes possessing amide fragments tethered to 4-(phenyldiazenyl)naphthalen-1-ol 3 were obtained in good overall yields from 1-hydroxy-2-naphthoic acid by consecutive conversion to amides $\mathbf{6}$ and diazo coupling as a one-pot two step protocol without intermediate purification. It was shown by quantum-chemical calculation and mass spectra that the products exist in enol form in gas phase, while the position of the equilibrium in solution is strongly dependent on the solvent both in UV and NMR concentration scale. It was found that the keto form of $\mathbf{3 b}$ crystallizes from acetone as dimer with hydrogen

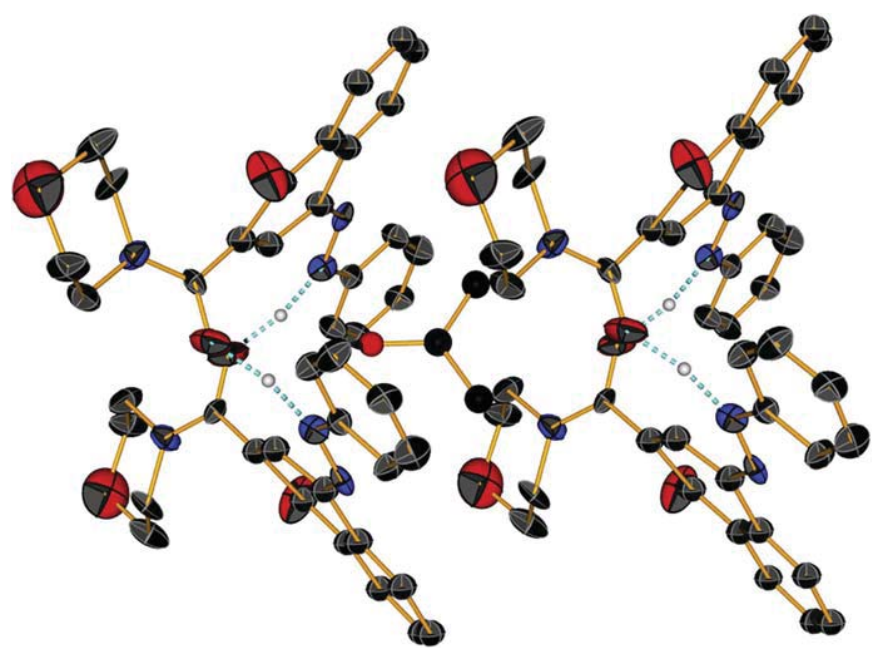

Fig. 7. 3D structure of $\mathbf{3 b}$; ellipsoids are in $30 \%$ probability. 


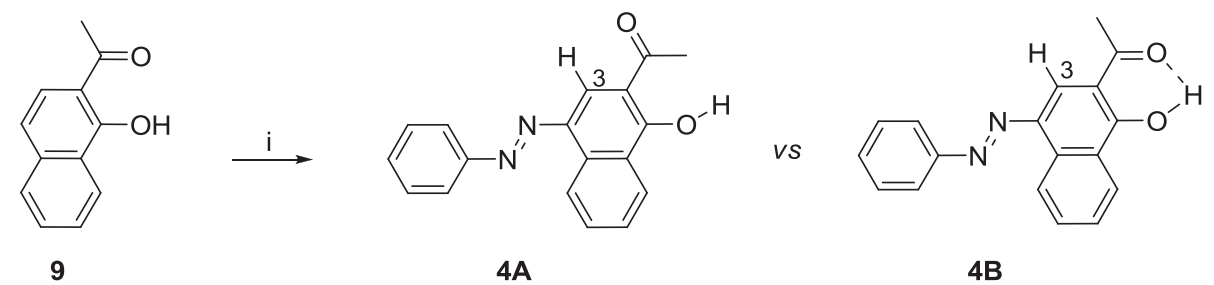

Scheme 4. i) $\mathrm{PhNH}_{2}$, conc. $\mathrm{HCl}, \mathrm{NaNO}_{2}$, acetone $-\mathrm{H}_{2} \mathrm{O}, \mathrm{NaOH}$.

bonding between $\mathrm{N}_{1}-H$ in the one molecule and amide $\mathrm{C}=\mathrm{O}$ in the other. A study on the switching and sensing properties of the products is in progress and will be reported in due course.

\section{Experimental section}

\subsection{Synthesis}

\subsubsection{General}

All reagents were purchased from Aldrich, Merck and Fluka and were used without any further purification. Fluka silica gel/TLCcards 60778 with fluorescent indicator $254 \mathrm{~nm}$ were used for TLC chromatography and $R_{\mathrm{f}}$-values determination. The high performance flash chromatography (HPFC) purifications were carried out on a Biotage Horizon ${ }^{\mathrm{TM}}$ system (Charlottesville, Virginia, USA) on silica gel. The melting points were determined in capillary tubes on SRS MPA100 OptiMelt (Sunnyvale, CA, USA) automated melting point system. The NMR spectra were recorded on a Bruker Avance II+ 600 spectrometer (Rheinstetten, Germany) with fid resolution $0.3 \mathrm{~Hz}$, i.e. $5.10^{-4} \mathrm{ppm}$; the chemical shifts were quoted in $\mathrm{ppm}$ in $\delta$-values against tetramethylsilane (TMS) as an internal standard and the coupling constants were calculated in $\mathrm{Hz}$. The assignment of the signals was confirmed by applying 2D techniques. The spectra were recorded as $10^{-1} \mathrm{M}$ solutions in deuterochloroform or deuteroacetone (where indicated) except NOESY experiments where $3 \times 10^{-2} \mathrm{M}$ solutions were used in order to avoid transmolecular interactions. For simplicity, the ester naphthol unit in $\mathbf{8}$ is described as basic, while the amide substituted moiety is designated as $(\mathrm{C}, \mathrm{H})^{\prime}$. The MS-spectra were recorded on a DFS High
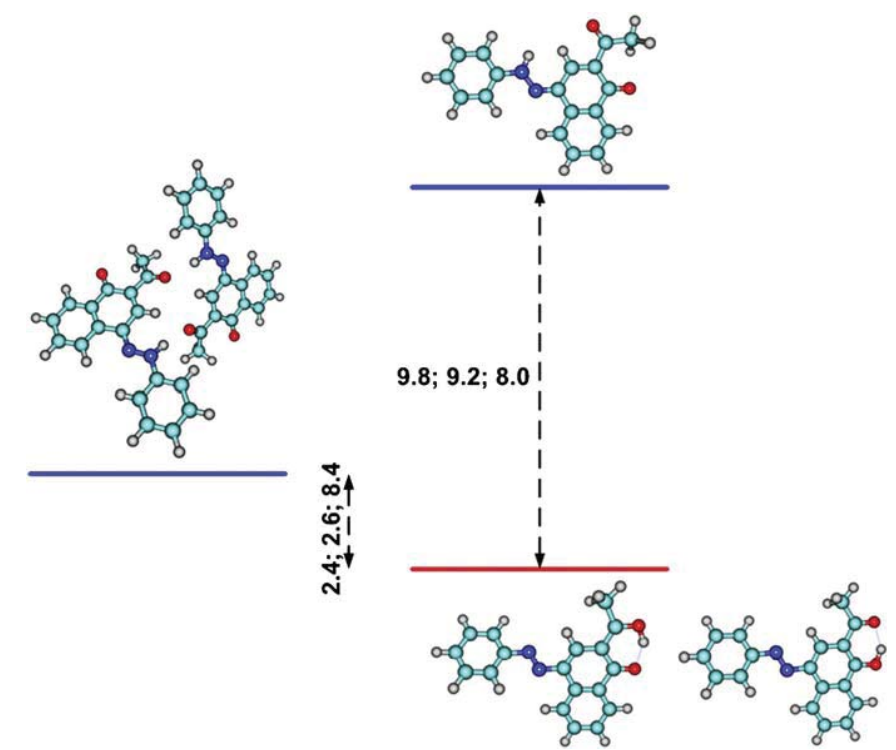

Fig. 8. Relative stability $\left(\mathrm{HF} / 6-31 \mathrm{G}^{* *}\right)$ of the tautomers of 4 . The values of the relative energy, relative energy $+\mathrm{ZPE}$ correction and $\Delta \Delta \mathrm{G}$ are given in $\mathrm{kcal} / \mathrm{mol}$ units.
Resolution Magnetic Sector MS Thermo Fisher Scientific GmbH (Bremen, Germany) instrument operating in EI mode at $70 \mathrm{eV}$ with an ion source temperature $220{ }^{\circ} \mathrm{C}$. The accurate mass measurements were performed using perfluorokerosene as a reference.

4.1.2. Amide coupling. Synthesis of 2-(piperidine-1-carbonyl) naphthalen-1-yl-1-hydroxy-2-naphthoate 8a

A mixture of 1-hydroxy-2-naphthoic acid $\mathbf{5}(5 \mathrm{mmol})$, piperidine ( $6 \mathrm{mmol}), \mathrm{EDCl}(6 \mathrm{mmol})$, and HOBT $(6 \mathrm{mmol})$ in dichloromethane $(25 \mathrm{ml}$ ) was stirred at room temperature for $18 \mathrm{~h}$. The reaction mixture was poured into ice-water and the solid phase was filtered off and washed with $\mathrm{CH}_{2} \mathrm{Cl}_{2}$. The products were partitioned between $\mathrm{CH}_{2} \mathrm{Cl}_{2}$ and water. The organic layer was washed with brine, dried over $\mathrm{Na}_{2} \mathrm{SO}_{4}$, and purified by flash chromatography on silica gel. Mobile phase with a gradient of polarity from $\mathrm{CH}_{2} \mathrm{Cl}_{2}$ to ether: $\mathrm{CH}_{2} \mathrm{Cl}_{2}=1: 9$ : $54 \%$ yield of $\mathbf{8 a} ; R_{\mathrm{f}} 0.54\left(\mathrm{CH}_{2} \mathrm{Cl}_{2}\right.$ :acetone $\left.95: 5\right)$; red crystals, m. p. $165-166{ }^{\circ} \mathrm{C} ;{ }^{1} \mathrm{H}$ NMR 1.439 (bm, $6 \mathrm{H}, \mathrm{CH}_{2}-3, \mathrm{CH}_{2}-4$ and $\mathrm{CH}_{2}-5$ piperidine), 3.272 (bm, $2 \mathrm{H}, 1 / 2 \mathrm{CH}_{2}-2$ and $\mathrm{CH}_{2}-6$ piperidine), 3.503 (bs, $2 \mathrm{H}, 1 / 4 \mathrm{CH}_{2}-2$ and $\mathrm{CH}_{2}-6$ piperidine), 3.579 (bs, $2 \mathrm{H}, 1 / 4 \mathrm{CH}_{2}-2$ and $\mathrm{CH}_{2}-6$ piperidine), 7.347 (d, $1 \mathrm{H}, \mathrm{J}$ 8.7, $\mathrm{CH}-4$ ), 7.380 (d, $1 \mathrm{H}, \mathrm{J}$ 8.7, $\left.\mathrm{CH}-3^{\prime}\right), 7.480\left(\mathrm{~m}, 3 \mathrm{H}, \mathrm{CH}-8, \mathrm{CH}-7^{\prime}\right.$ and $\left.\mathrm{CH}-8^{\prime}\right), 7.591$ (ddd, 1H, J 1.2, 7.0, 8.2, CH-7), 7.759 (d, 1H, J 8.2, CH-6), 7.788 (d, 1H, J 8.5, $\mathrm{CH}-4^{\prime}$ ), 7.831 (dd, $1 \mathrm{H}, \mathrm{J} 1.2,8.5, \mathrm{CH}-9^{\prime}$ ), 7.847 (dd, $1 \mathrm{H}, \mathrm{J} \mathrm{1.2,} \mathrm{8.4,}$ $\left.\mathrm{CH}-6^{\prime}\right), 8.062$ (d, 1H, J 8.7, CH-3), 8.364 (d, 1H, J 8.3, CH-9), 11.492 (s, $1 \mathrm{H}, \mathrm{OH}) ;{ }^{13} \mathrm{C}$ NMR $23.37\left(\mathrm{CH}_{2}-3, \mathrm{CH}_{2}-4\right.$ or $\mathrm{CH}_{2}-5$ piperidine), $24.54\left(\mathrm{CH}_{2}-3, \mathrm{CH}_{2}-4\right.$ or $\mathrm{CH}_{2}-5$ piperidine $), 25.42\left(\mathrm{CH}_{2}-3, \mathrm{CH}_{2}-4\right.$ or $\mathrm{CH}_{2}-5$ piperidine), $41.68\left(\mathrm{CH}_{2}-2\right.$ or $\mathrm{CH}_{2}-6$ piperidine $), 47.31\left(\mathrm{CH}_{2}-2\right.$ or $\mathrm{CH}_{2}-6$ piperidine), $103.45\left(\mathrm{C}_{\text {quat }}-2\right), 118.35(\mathrm{CH}-4), 120.75\left(\mathrm{CH}-9^{\prime}\right)$, $122.87\left(\mathrm{CH}-3^{\prime}\right), 123.01(\mathrm{CH}-9), 123.32(\mathrm{CH}-3), 123.69$ ( $\left.\mathrm{C}_{\text {quat }}-10\right)$, $125.08(\mathrm{CH}-8), 125.69\left(C_{\text {quat }}-10^{\prime}\right), 125.94\left(\mathrm{CH}-4^{\prime}\right), 126.05\left(C_{\text {quat }}-2^{\prime}\right)$, $126.34\left(\mathrm{CH}-7^{\prime}\right), 126.47\left(\mathrm{CH}-8^{\prime}\right), 126.62(\mathrm{CH}-6), 127.11\left(\mathrm{CH}-6^{\prime}\right), 129.04$ (CH-7), 133.52 ( $\left.C_{\text {quat }}-5^{\prime}\right), 136.70$ ( $\left.C_{\text {quat }}-5\right), 141.50\left(C_{\text {quat }}{ }^{\prime}{ }^{\prime}\right), 161.09$

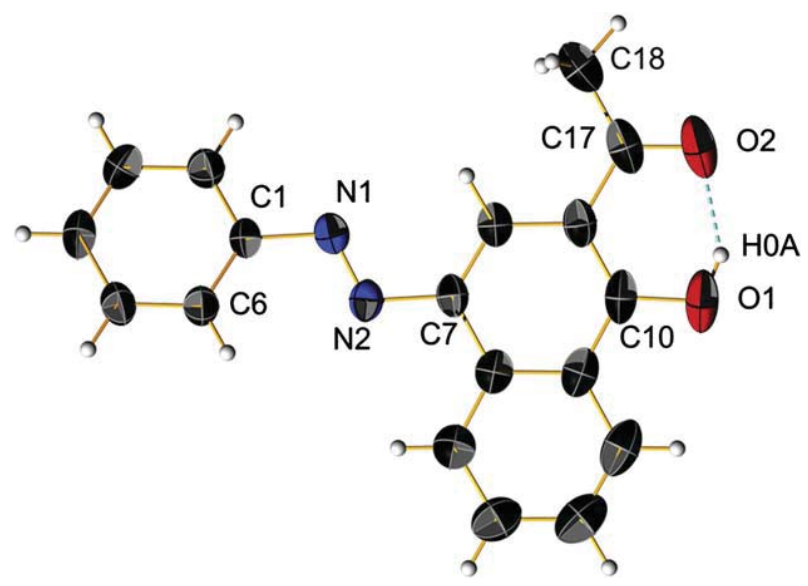

Fig. 9. View of the molecular structure of $4,30 \%$ of probability. $\mathrm{H}$ atoms are presented with spheres of arbitrary radii. H-bond is shown in dashed blue. (For interpretation of the references to colour in this figure legend, the reader is referred to the web version of this article.) 
$\left(C_{\text {quat }}-1\right), 165.23$ ( $C_{\text {quat }}$-CO'), 168.41 ( $C_{\text {quat }}$-CO); COSY cross peaks $1.439 / 3.272,1.439 / 3.503,1.439 / 3.579,7.347 / 8.062,7.380 / 7.788$, 7.480/7.591, 7.480/7.831, 7.480/7.847, 7.480/8.364, 7.591/7.759; NOESY cross peaks $1.439 / 3.272,1.439 / 3.503$ (weak), 1.439/3.579 (weak), 3.272/3.503, 3.272/3.579, 3.503/7.380, 7.347/7.759, 7.347/ 8.062, 7.380/7.788, 7.480/7.591, 7.480/7.831, 7.480/7.847, 7.480/ 8.364, 7.591/7.759, 7.788/7.847, 7.831/11.492 (weak), 8.364/11.492; HSQC cross peaks $1.439 / 24.54,1.439 / 25.42,1.439 / 23.37,3.272 /$ 47.31, 3.503/41.68, 3.579/41.68, 7.347/118.35, 7.380/122.87, 7.480/ 125.08, 7.480/126.34, 7.480/126.47, 7.591/129.04, 7.759/126.62, $7.788 / 125.94, \quad 7.831 / 120.75, \quad 7.847 / 127.11, \quad 8.062 / 123.32, \quad 8.364 /$ 123.01; HMBC cross peaks 7.347/103.45, 7.347/123.69, 7.347/ 126.62, 7.347/136.70, 7.347/161.09 (weak), 7.380/133.52, 7.380/ $141.50,7.380 / 165.23,7.480 / 120.75,7.480 / 123.69,7.480 / 125.69$, $7.480 / 126.62, \quad 7.480 / 127.11, \quad 7.480 / 133.52, \quad 7.591 / 123.01, \quad 7.591 /$ 136.70, 7.759/118.35, 7.759/123.69, 7.759/125.08, 7.759/136.70 (weak), 7.759/161.09 (weak), 7.788/125.69, 7.788/126.05, 7.788/ 127.11, 7.788/133.52 (weak), 7.788/141.50 (weak), 7.831/126.34, $7.831 / 133.52, \quad 7.831 / 141.50, \quad 7.847 / 125.69, \quad 7.847 / 125.94, \quad 7.847 \mid$ 126.47, 8.062/136.70, 8.062/161.09, 8.062/168.41, 8.364/129.04, $8.364 / 136.70,8.364 / 161.09,11.492 / 103.45,11.492 / 123.69,11.492 /$ 136.70 (weak), 11.492/161.09; $\mathrm{m} / \mathrm{z}$ (EI) 425 (4, M ${ }^{+}$), 255 (100), 238 (7), 170 (88), 143 (13), 114 (48\%); HRMS (EI): $\mathrm{M}^{+}$, found 425.1626. $\mathrm{C}_{27} \mathrm{H}_{23} \mathrm{NO}_{4}$ requires 425.1627 .

\subsubsection{Synthesis of amides 6}

4.1.3.1. Method 1. A solution of 1-hydroxy-2-naphthoic acid 5 $(5 \mathrm{mmol}, 911 \mathrm{mg})$ in $\mathrm{SOCl}_{2}(10 \mathrm{ml})$ was refluxed for $4 \mathrm{~h}$. The excess of $\mathrm{SOCl}_{2}$ was evaporated to dryness. To a solution of piperidine (20 mmol, $2 \mathrm{ml}$ ) in dry $\mathrm{CH}_{2} \mathrm{Cl}_{2}(40 \mathrm{ml})$ a solution of the crude acyl chloride in $\mathrm{CH}_{2} \mathrm{Cl}_{2}(10 \mathrm{ml})$ was added at $0{ }^{\circ} \mathrm{C}$ and the mixture was stirred at room temperature overnight. The products were partitioned between $\mathrm{CH}_{2} \mathrm{Cl}_{2}$ and aq. $\mathrm{Na}_{2} \mathrm{CO}_{3}$. The organic phase was washed with brine, $2 \mathrm{~N} \mathrm{HCl}$, and again with brine, was dried over $\mathrm{Na}_{2} \mathrm{SO}_{4}$, and evaporated to dryness. The product was purified by flash chromatography on silica gel. Pure products were isolated after the third purification: $25 \% \mathbf{6 a}, 13 \% \mathbf{7 a}$, and $<1 \% \mathbf{8 a}$.

4.1.3.1.1. (1-Hydroxynaphthalen-2-yl)(piperidin-1-yl)methanone 6a. $R_{\mathrm{f}} 0.71\left(\mathrm{CH}_{2} \mathrm{Cl}_{2}\right.$ :acetone $\left.95: 5\right), R_{\mathrm{f}} 0.30\left(\mathrm{CH}_{2} \mathrm{Cl}_{2}\right)$; light yellow crystals, m. p. $108-109{ }^{\circ} \mathrm{C} ;{ }^{1} \mathrm{H}$ NMR $1.700\left(\mathrm{~m}, 6 \mathrm{H}, \mathrm{CH}_{2}-3, \mathrm{CH}_{2}-4\right.$ and

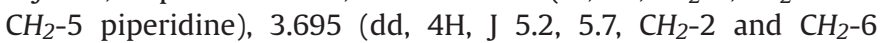
piperidine), 7.266 (d, 1H, J 8.5, CH-4), 7.290 (d, 1H, J 8.6, CH-3), 7.505 (ddd, 1H, J 1.3, 6.9, 8.3, CH-8), 7.559 (ddd, $1 \mathrm{H}, \mathrm{J} 1.3,6.8,8.1, \mathrm{CH}-7$ ), 7.758 (d, 1H, J 8.0, CH-6), 8.377 (dt, 1H, J 0.6, 8.3, CH-9), 11.273 (s, 1H, $\mathrm{OH}) ;{ }^{13} \mathrm{C}$ NMR $24.59\left(\mathrm{CH}_{2}-4\right.$ piperidine), $26.17\left(\mathrm{CH}_{2}-3\right.$ and $\mathrm{CH}_{2}-5$ piperidine), $47.14\left(\mathrm{CH}_{2}-2\right.$ and $\mathrm{CH}_{2}-6$ piperidine), 109.52 ( $\left.\mathrm{C}_{\text {quat }}-2\right)$, 117.50 ( $\mathrm{CH}-4), 123.56$ (CH-9), 124.44 ( $\mathrm{CH}-3), 125.53$ ( $\left.\mathrm{C}_{\text {quat }}-10\right)$, 125.63 (CH-8), 127.28 (CH-6), 128.37 (CH-7), 135.48 ( $\left.C_{\text {quat }}-5\right), 158.14$ $\left(C_{\text {quat }}-1\right), 172.11(C=0)$; COSY cross peaks $1.700 / 3.695$, 3.659/7.290, $7.266 / 7.290,7.505 / 7.559,7.505 / 8.377,7.559 / 7.758$; NOESY cross peaks $1.700 / 3.695,7.266 / 7.290,7.266 / 7.758,7.266 / 7.758,7.505 /$ 7.559, 7.505/8.377, 7.559/7.758, 8.377/11.273; HSQC cross peaks $1.700 / 24.59,1.700 / 26.17,3.695 / 47.14,7.266 / 117.50,7.290 / 124.44$, $7.505 / 125.63,7.559 / 128.37,7.758 / 127.28,8.377 / 123.56$; НMBC cross peaks $1.700 / 24.59,1.700 / 26.17,1.700 / 47.14,3.695 / 24.59$, 3.695/26.17, 3.695/47.14, 3.695/172.11, 7.266/109.52, 7.266/125.53, $7.266 / 127.28, \quad 7.290 / 135.48, \quad 7.290 / 158.14, \quad 7.290 / 172.11, \quad 7.505 /$ $125.53,7.505 / 127.28,7.559 / 123.56,7.559 / 135.48,7.758 / 117.50$, 7.758/125.53, 7.758/125.63, 7.758/135.48 (weak), 8.377/128.37, 8.377/135.48, 8.377/158.14, 11.273/109.52 (weak), 11.273/125.53, 11.273/158.14 (weak); $m / z$ (EI) 255 (88, $\mathrm{M}^{+}$), 238 (11), 170 (100), 143 (22), 115 (81\%); HRMS (EI): $\mathrm{M}^{+}$, found 255.1257. $\mathrm{C}_{16} \mathrm{H}_{17} \mathrm{NO}_{2}$ requires 255.1259.

4.1.3.1.2. (4-Chloro-1-hydroxynaphthalen-2-yl)(piperidin-1-yl) methanone 7a. $R_{\mathrm{f}} 0.68\left(\mathrm{CH}_{2} \mathrm{Cl}_{2}\right.$ :acetone 95:5), $R_{\mathrm{f}} 0.43\left(\mathrm{CH}_{2} \mathrm{Cl}_{2}\right)$; light yellow crystals, m. p. $118-119{ }^{\circ} \mathrm{C} ;{ }^{1} \mathrm{H}$ NMR $1.622\left(\mathrm{~m}, 4 \mathrm{H}, \mathrm{CH}_{2}-3\right.$, and $\mathrm{CH}_{2}-5$ piperidine), 1.667 ( $\mathrm{m}, 2 \mathrm{H}, \mathrm{CH}_{2}-4$ piperidine), 3.623 (dd, $4 \mathrm{H}$, J 5.2, 5.7, $\mathrm{CH}_{2}-2$ and $\mathrm{CH}_{2}-6$ piperidine), $7.316(\mathrm{~s}, 1 \mathrm{H}, \mathrm{CH}-3), 7.508$ (ddd, 1H, J 1.2, 6.9, 8.2, CH-8), 7.615 (ddd, 1H, J 1.3, 6.9, 8.3, CH-7), 8.084 (dt, 1H, J 0.7, 8.4, CH-6), 8.343 (ddd, 1H, J 0.6, 1.2, 8.3, CH-9), 11.240 (s, 1H, OH); ${ }^{13} \mathrm{C}$ NMR $24.51\left(\mathrm{CH}_{2}-4\right.$ piperidine $), 26.12\left(\mathrm{CH}_{2}-3\right.$ and $\mathrm{CH}_{2}-5$ piperidine), $47.19\left(\mathrm{CH}_{2}-2\right.$ and $\mathrm{CH}_{2}-6$ piperidine), 109.54 ( $\left.C_{\text {quat }}-2\right), 120.64$ ( $\left.C_{\text {quat }}-4\right), 124.00$ (CH-9), 124.05 (CH-3), 124.22 (CH-6), 126.42 (CH-8), 126.62 ( $\left.\mathrm{C}_{\text {quat }}-10\right), 129.43$ (CH-7), 132.47 $\left(C_{\text {quat }}-5\right), 157.33$ ( $\left.C_{\text {quat }}-1\right), 170.95(C=0)$; COSY cross peaks 1.622 / $1.667,1.622 / 3.623,1.667 / 3.623,7.508 / 7.615,7.508 / 8.343,7.615 /$ 8.084; NOESY cross peaks 1.622/1.667, 1.622/3.623, 3.623/7.316, $7.508 / 7.615,7.508 / 8.343,7.615 / 8.084,8.343 / 11.240$; HSQC cross peaks $1.622 / 26.12,1.667 / 24.51,3.623 / 47.19,7.316 / 124.05,7.508 /$ 126.42, 7.615/129.43, 8.084/124.22, 8.343/124.00; HMBC cross peaks $1.622 / 24.51,1.622 / 26.12,1.622 / 47.19$ (weak), 1.667/26.12, 3.623/24.51, 3.623/26.12, 3.623/47.19, 3.623/170.95, 7.316/120.64, $7.316 / 132.47, \quad 7.316 / 157.33, \quad 7.316 / 170.95, \quad 7.508 / 124.22, \quad 7.508 /$ 126.62 , 7.615/124.00, 7.615/132.47, 8.084/120.64, 8.084/126.42, 8.343/120.64 (weak), 8.343/129.43, 8.343/132.47, 8.343/157.33, 11.240/109.54 (weak), 11.240/126.62, 11.240/157.33 (weak); $m / z$ (EI) $289\left(100, \mathrm{M}^{+}\right), 254$ (16), 203 (72), 170 (7), 149 (44), 113 (21\%); HRMS (EI): $\mathrm{M}^{+}$, found 289.0864. $\mathrm{C}_{16} \mathrm{H}_{16} \mathrm{ClNO}_{2}$ requires 289.0870 .

4.1.3.2. Method 2. To a solution of 1-hydroxy-2-naphthoic acid 5 $(5 \mathrm{mmol})$ in DMF $(0.1 \mathrm{ml})$ and heptane $(20 \mathrm{ml}) \mathrm{SOCl}_{2}(20 \mathrm{mmol})$ was added and the solution was refluxed for $4 \mathrm{~h}$. The excess of $\mathrm{SOCl}_{2}$ and solvents were evaporated to dryness. To the crude acyl chloride in $\mathrm{CH}_{2} \mathrm{Cl}_{2}(20 \mathrm{ml}) \mathrm{EtN}(i-\mathrm{Pr})_{2}(15 \mathrm{mmol})$ and piperidine or morpholine (6 mmol) was added at $0{ }^{\circ} \mathrm{C}$ and the mixture was stirred at room temperature for $4-5 \mathrm{~h}$. The products were partitioned between $\mathrm{CH}_{2} \mathrm{Cl}_{2}$ and aq. $\mathrm{Na}_{2} \mathrm{CO}_{3}$. The organic phase was washed with brine, $2 \mathrm{~N} \mathrm{HCl}$, and again with brine, was dried over $\mathrm{Na}_{2} \mathrm{SO}_{4}$, and evaporated to dryness. The product was purified by HPFC on silica gel: $44 \% \mathbf{6 a}$ and $13 \% \mathbf{8 a} ; 42 \% \mathbf{6 b}$ and $16 \% \mathbf{8 b}$.

4.1.3.2.1. (1-Hydroxynaphthalen-2-yl)(morpholine-1-yl)methanone 6b. $R_{\mathrm{f}} 0.61\left(\mathrm{CH}_{2} \mathrm{Cl}_{2}\right.$ :acetone 95:5), $R_{\mathrm{f}} 0.12\left(\mathrm{CH}_{2} \mathrm{Cl}_{2}\right)$; light yellow crystals, m. p. $131-132{ }^{\circ} \mathrm{C}$; ${ }^{1} \mathrm{H}$ NMR $3.759\left(\mathrm{~m}, 4 \mathrm{H}, \mathrm{CH}_{2}-\mathrm{O}\right.$ morpholine), 3.801 ( $\mathrm{m}, 4 \mathrm{H}, \mathrm{CH}_{2}-\mathrm{N}$ morpholine), 7.257 (d, 1H, J 8.7, $\mathrm{CH}-3$ ), 7.281 (d, 1H, J 8.7, CH-4), 7.520 (ddd, 1H, J 1.2, 6.8, 8.3, CH-8), 7.576 (ddd, 1H, J 1.3, 6.9, 8.2, CH-7), 7.761 (dt, 1H, J 0.8, 8.1, CH-6), 8.385 (ddd, $1 \mathrm{H}, \mathrm{J}$ 0.6, 1.3, 8.3, CH-9), $11.177(\mathrm{~s}, 1 \mathrm{H}, \mathrm{OH}) ;{ }^{13} \mathrm{C}$ NMR 46.48 $\left(\mathrm{CH}_{2}-\mathrm{N}\right.$ morpholine), $66.93\left(\mathrm{CH}_{2}-\mathrm{O}\right.$ morpholine $), 108.56$ ( $\left.\mathrm{C}_{\text {quat }}-2\right)$, 117.77 (CH-4), 123.60 (CH-9), 124.01 (CH-3), 125.53 ( $\left.C_{\text {quat }}-10\right)$, $125.80(\mathrm{CH}-8), 127.30$ (CH-6), $128.64(\mathrm{CH}-7), 135.63\left(C_{\text {quat }}-5\right), 158.52$ $\left(C_{\text {quat }}-1\right), 172.30(C=0)$; COSY cross peaks $3.759 / 3.801,7.257 / 7.281$, $7.520 / 7.576,7.520 / 8.385,7.576 / / 7.761$; NOESY cross peaks $3.759 /$ 3.801, 3.759/7.257, 3.759/11.177 (weak), 3.801/7.257, 3.801/11.177 (weak), 7.257/7.281, 7.281/7.761, 7.520/7.576, 7.520/8.385, 7.576/ 7.761, 8.385/11.177; HSQC cross peaks 3.759/66.93, 3.801/46.48, $7.257 / 124.01, \quad 7.281 / 117.77, \quad 7.520 / 125.80, \quad 7.576 / 128.64, \quad 7.761 /$ 127.30, 8.385/123.60; HMBC cross peaks 3.759/46.48, 3.759/66.93, 3.801/46.48, 3.801/66.93, 3.801/172.30, 7.257/135.63, 7.257/158.52, $7.257 / 172.30, \quad 7.281 / 108.56, \quad 7.281 / 125.53, \quad 7.281 / 127.30, \quad 7.520 /$ 125.53, 7.520/127.30, 7.576/123.60, 7.576/135.63, 7.761/117.77, $7.761 / 125.53,7.761 / 125.80,7.761 / 135.63$ (weak), 8.385/128.64, $8.385 / 135.63,8.385 / 158.52,11.177 / 108.56,11.177 / 125.53,11.177 \mid$ 158.52; m/z (EI) $257\left(68, \mathrm{M}^{+}\right), 213$ (3), 170 (100), 143 (8), 115 (16\%); HRMS (EI): $\mathrm{M}^{+}$, found 257.1048. $\mathrm{C}_{15} \mathrm{H}_{15} \mathrm{NO}_{3}$ requires 257.1052 .

4.1.3.2.2. 2-(Morpholine-1-carbonyl)naphthalen-1-yl-1-hydroxy2-naphthoate $\boldsymbol{8 b}$. $R_{\mathrm{f}} 0.42\left(\mathrm{CH}_{2} \mathrm{Cl}_{2}\right.$ :acetone $\left.95: 5\right)$; light yellow crystals, m. p. $142.5-143^{\circ} \mathrm{C} ;{ }^{1} \mathrm{H}$ NMR 3.448 ( $\mathrm{m}, 4 \mathrm{H}, \mathrm{CH}_{2}-\mathrm{N}$ morpholine), $3.620\left(\mathrm{~m}, 4 \mathrm{H}, \mathrm{CH}_{2}-\mathrm{O}\right.$ morpholine), 7.450 (d, 1H, J 8.9, $\left.\mathrm{CH}-4\right), 7.458$ (d, $\left.1 \mathrm{H}, \mathrm{J} 8.5, \mathrm{CH}_{-} 3^{\prime}\right), 7.585\left(\mathrm{~m}, 3 \mathrm{H}, \mathrm{CH}-8, \mathrm{CH}-7^{\prime}\right.$ and $\left.\mathrm{CH}-8^{\prime}\right), 7.688$ (ddd, 1H, J 1.3, 7.0, 8.2, CH-7), 7.849 (d, 1H, J 8.2, CH-6), 7.883 (d, 1H, 
J 8.4, $\left.\mathrm{CH}-4^{\prime}\right), 7.938$ (dd, $\left.1 \mathrm{H}, \mathrm{J} 1.2,8.4, \mathrm{CH}-6^{\prime}\right), 7.943$ (dd, $1 \mathrm{H}, \mathrm{J} 0.9,8.3$ CH-9'), 8.146 (d, 1H, J 8.8, CH-3), 8.454 (ddd, $1 \mathrm{H}, \mathrm{J} 0.5,1.0,8.3, \mathrm{CH}-9$ ), $11.511(\mathrm{~s}, 1 \mathrm{H}, \mathrm{OH}) ;{ }^{13} \mathrm{C}$ NMR $47.69\left(\mathrm{CH}_{2}-\mathrm{N}\right.$ morpholine $), 66.92$ ( $\mathrm{CH}_{2}-\mathrm{O}$ morpholine), 104.33 ( $\left.\mathrm{C}_{\text {quat }}-2\right)$, 119.59 ( $\left.\mathrm{CH}-4\right), 121.83$ ( $\mathrm{CH}-$ 9'), 123.77 ( $\left.\mathrm{CH}-3^{\prime}\right), 124.13$ (CH-9), 124.19 (CH-3), 124.75 (C (quat $\left.^{-10}\right)$, $125.62\left(C_{\text {quat }}-10^{\prime}\right), 126.25(\mathrm{CH}-8), 127.07\left(C_{\text {quat }}-2^{\prime}\right), 127.10\left(\mathrm{CH}-4^{\prime}\right)$, $127.69(\mathrm{CH}-6), 127.72\left(\mathrm{CH}-7^{\prime}\right.$ and $\left.\mathrm{CH}-8^{\prime}\right), 128.18\left(\mathrm{CH}^{\prime} 6^{\prime}\right), 130.24(\mathrm{CH}-$ $7), 134.77\left(C_{\text {quat }}{ }^{-5}\right), 137.81\left(C_{\text {quat }}{ }^{-5}\right), 142.87\left(C_{\text {quat }^{-}}{ }^{\prime}\right), 162.28\left(C_{\text {quat }}{ }^{-}\right.$ $1), 166.66$ ( $\left(C_{\text {quat }}-\mathrm{CO}^{\prime}\right), 169.48\left(C_{\text {quat }}-\mathrm{CO}\right)$; COSY cross peaks $3.448 /$ $3.620,7.450 / 8.146,7.458 / 7.883,7.585 / 7.688,7.585 / 7.938,7.585 /$ $7.943,7.585 / 8.454,7.688 / 7.849$; NOESY cross peaks 3.448/3.620, 3.448/7.458, 3.620/7.458 (weak), 3.620/11.511 (weak), 7.450/7.849, $7.450 / 8.146,7.458 / 7.883,7.585 / 7.688,7.585 / 7.938,7.585 / 7.943$, $7.585 / 8.454,7.688 / 7.849,7.883 / 7.938,8.454 / 11.511$; HSQC cross peaks 3.448/47.69, 3.620/66.92, 7.450/119.59, 7.458/123.77, 7.585/ $126.25, \quad 7.585 / 127.72,7.688 / 130.24,7.849 / 127.69,7.883 / 127.10$, $7.938 / 128.18,7.943 / 121.83,8.146 / 124.19,8.454 / 124.13$; HMBC cross peaks 3.448/66.92, 3.448/166.66, 3.620/47.69, 7.450/104.33, 7.450/ $124.75,7.450 / 127.69,7.458 / 134.77,7.458 / 142.87,7.458 / 166.66$, $7.585 / 121.83, \quad 7.585 / 124.75, \quad 7.585 / 125.62, \quad 7.585 / 127.69,7.585 /$ $128.18, \quad 7.585 / 134.77, \quad 7.688 / 124.13, \quad 7.688 / 137.81, \quad 7.849 / 119.59$, $7.849 / 124.75, \quad 7.849 / 126.25, \quad 7.883 / 125.62, \quad 7.883 / 127.07, \quad 7.883 /$ 128.18, 7.883/134.77 (weak), 7.883/142.87 (weak), 7.938/125.62, $7.938 / 127.10, \quad 7.938 / 127.72, \quad 7.943 / 127.72, \quad 7.943 / 134.77, \quad 7.943 /$ 142.87, 8.146/137.81, 8.146/162.28, 8.146/169.48, 8.454/130.24, $8.454 / 137.81,8.454 / 162.28,11.511 / 104.33,11.511 / 124.75,11.511 /$ 162.28; $\mathrm{m} / z$ (EI) $427\left(3, \mathrm{M}^{+}\right), 257$ (51), 213 (4), 170 (100), 143 (12), $114(37 \%)$; HRMS (EI): $\mathrm{M}^{+}$, found 427.1414. $\mathrm{C}_{26} \mathrm{H}_{21} \mathrm{NO}_{5}$ requires 427.1420 .

4.1.3.3. Method 3. To a solution of 1-hydroxy-2-naphthoic acid 5 $(5 \mathrm{mmol})$ in DMF $(0.1 \mathrm{ml})$ and heptane $(20 \mathrm{ml}) \mathrm{SOCl}_{2}(12.5 \mathrm{mmol})$ was added and the solution was refluxed for $4 \mathrm{~h}$. The excess of $\mathrm{SOCl}_{2}$ and solvents were evaporated to dryness. To the crude acyl chloride in $\mathrm{CH}_{2} \mathrm{Cl}_{2}(20 \mathrm{ml}) \mathrm{EtN}(i-\mathrm{Pr})_{2}(15 \mathrm{mmol})$ and amine $(6 \mathrm{mmol})$ was added at $0{ }^{\circ} \mathrm{C}$ and the mixture was stirred at room temperature for 4-5 h. The products were partitioned between $\mathrm{CH}_{2} \mathrm{Cl}_{2}$ and aq. $\mathrm{Na}_{2} \mathrm{CO}_{3}$. The organic phase was washed with brine, $2 \mathrm{~N} \mathrm{HCl}$, and again with brine, was dried over $\mathrm{Na}_{2} \mathrm{SO}_{4}$, and evaporated to dryness to give the crude products which were directly used in the next step. Small portion of $\mathbf{6 c}$ was purified by HPFC on silica gel for characterization.

4.1.3.3.1. (1-Hydroxynaphthalen-2-yl)(4-phenylpiperazine-1-yl) methanone $6 c$. $R_{\mathrm{f}} 0.69\left(\mathrm{CH}_{2} \mathrm{Cl}_{2}\right.$ :acetone $\left.95: 5\right), R_{\mathrm{f}} 0.22\left(\mathrm{CH}_{2} \mathrm{Cl}_{2}\right) ; \mathrm{m}$. p. 146-147 ${ }^{\circ} \mathrm{C}$; ${ }^{1} \mathrm{H}$ NMR 3.179 (t, $4 \mathrm{H}, \mathrm{J}$ 5.1, $\mathrm{CH}_{2}-3$ and $\mathrm{CH}_{2}-5$ piperazine), 3.853 (t, 4H, J 5.1, $\mathrm{CH}_{2}-2$ and $\mathrm{CH}_{2}-6$ piperazine), $6.844(\mathrm{tt}, 1 \mathrm{H}$, $\mathrm{J}$ 0.9, 7.3, $\mathrm{CH}-4 \mathrm{~N}-\mathrm{Ph}$ ), 6.865 (dd, $2 \mathrm{H}, \mathrm{J} 0.9,8.9, \mathrm{CH}-2$ and $\mathrm{CH}-6$ $\mathrm{N}-\mathrm{Ph}$ ), $7.223(\mathrm{~m}, 4 \mathrm{H}, \mathrm{CH}-3 \mathrm{Ar}, \mathrm{CH}-4 \mathrm{Ar}$, and $\mathrm{CH}-3$ and $\mathrm{CH}-5 \mathrm{~N}-\mathrm{Ph}$ ), 7.441 (ddd, 1H, J 1.2, 6.8, 8.2, CH-8 Ar), 7.499 (ddd, 1H, J 1.3, 6.8, 8.2, CH-7 Ar), 7.693 (d, 1H, J 8.2, CH-6 Ar), 8.316 (dt, 1H, J 0.6, 8.3, CH-9 $\mathrm{Ar}), 11.170(\mathrm{~s}, 1 \mathrm{H}, \mathrm{OH}) ;{ }^{13} \mathrm{C}$ NMR $45.99\left(\mathrm{CH}_{2}-2\right.$ and $\mathrm{CH}_{2}-6$ piperazine $)$, $49.74\left(\mathrm{CH}_{2}-3\right.$ and $\mathrm{CH}_{2}-5$ piperazine), 108.81 ( $\left.\mathrm{C}_{\text {quat }}-2 \mathrm{Ar}\right), 116.70$ $(\mathrm{CH}-2$ and $\mathrm{CH}-6 \mathrm{~N}-\mathrm{Ph}), 117.80(\mathrm{CH}-4 \mathrm{Ar}), 120.71(\mathrm{CH}-4 \mathrm{~N}-\mathrm{Ph})$, 123.66 (CH-9 Ar), 124.26 (CH-3 Ar), 125.55 ( $\left.C_{\text {quat }}-10 \mathrm{Ar}\right), 125.85(\mathrm{CH}-$ $8 \mathrm{Ar}), 127.37$ (CH-6 Ar), $128.69(\mathrm{CH}-7 \mathrm{Ar}), 129.33(\mathrm{CH}-3$ and $\mathrm{CH}-5$ $\mathrm{N}-\mathrm{Ph}), 135.66$ ( $\left.C_{\text {quat }}-5 \mathrm{Ar}\right), 150.83$ ( $\left.C_{\text {quat }}-1 \mathrm{~N}-\mathrm{Ph}\right), 158.55$ ( $C_{\text {quat }}-1$ Ar), $172.38(C=0)$; COSY cross peaks $3.179 / 3.853,6.844 / 7.223$, $6.865 / 7.223,7.441 / 7.499,7.441 / 8.316,7.499 / 7.693$; NOESY cross peaks 3.179/3.853, 3.179/7.223 (weak), 3.853/7.223, 6.844/7.223, $6.865 / 7.223,7.223 / 7.693,7.441 / 7.499,7.441 / 8.316,7.499 / 7.693$, 8.316/11.170 (weak); HSQC cross peaks 3.179/49.74, 3.853/45.99, $6.844 / 120.71, \quad 6.865 / 116.70, \quad 7.223 / 117.80, \quad 7.223 / 124.26, \quad 7.223 /$ 129.33, 7.441/125.85, 7.499/128.69, 7.693/127.37, 8.316/123.66; HMBC cross peaks 3.179/45.99, 3.179/49.74, 3.179/150.83, 3.853/ $45.99,3.853 / 49.74,3.853 / 172.38,6.844 / 116.70,6.865 / 116.70,6.865 /$
120.71, 6.865/129.33 (weak), 6.865/150.83, 7.223/108.81, 7.223/ $116.70,7.223 / 120.71$ (weak), 7.223/125.55, 7.223/129.33, 7.223/ 135.66, 7.223/150.83, 7.223/158.55, 7.223/172.38, 7.441/125.55, $7.441 / 127.37, \quad 7.499 / 123.66, \quad 7.499 / 135.66, \quad 7.693 / 117.80, \quad 7.693 /$ $125.55,7.693 / 125.85,7.693 / 135.66$ (weak), 8.316/128.69, 8.316/ 135.66, 8.316/158.55, 11.170/108.81, 11.170/125.55, 11.170/158.55. $\mathrm{m} / z$ (EI) $332\left(75, \mathrm{M}^{+}\right), 213$ (97), 145 (31), 132 (100\%); HRMS (EI): $\mathrm{M}^{+}$, found 332.1522. $\mathrm{C}_{21} \mathrm{H}_{20} \mathrm{~N}_{2} \mathrm{O}_{2}$ requires 332.1525.

\subsubsection{Diazo coupling}

To aniline $(4 \mathrm{mmol})$ ice, conc. $\mathrm{HCl}(1.2 \mathrm{ml})$, and a solution of $\mathrm{NaNO}_{2}(4.4 \mathrm{mmol})$ in $\mathrm{H}_{2} \mathrm{O}(10 \mathrm{ml})$ were subsequently added and the mixture was stirred at $0{ }^{\circ} \mathrm{C}$ for $5 \mathrm{~min}$ to form a diazonium salt. To a solution of crude amide $\mathbf{6}$ or ketone $\mathbf{9}(4 \mathrm{mmol})$ in acetone $(25 \mathrm{ml})$ $10 \%$ aq. $\mathrm{NaOH}(4 \mathrm{ml})$ and then the solution of the diazonium salt were subsequently added at $0{ }^{\circ} \mathrm{C}$. The products were partitioned between water and $\mathrm{CH}_{2} \mathrm{Cl}_{2}$. The organic phase was washed with water, dried over $\mathrm{Na}_{2} \mathrm{SO}_{4}$, and purified by HPFC on silica gel.

4.1.4.1. (1-Hydroxy-4-(phenyldiazenyl)naphthalen-2-yl)(piperidin-1$y$ l)methanone $3 \boldsymbol{a}$. Starting from crude $\mathbf{6 a} ; 52 \%$ overall yield; $R_{\mathrm{f}}$ $0.53\left(\mathrm{CH}_{2} \mathrm{Cl}_{2}\right.$ :acetone 95:5); red crystals, m. p. $180.5-181{ }^{\circ} \mathrm{C} ;{ }^{1} \mathrm{H}$ NMR 1.726 (bs, $6 \mathrm{H}, \mathrm{CH}_{2}-3, \mathrm{CH}_{2}-4$ and $\mathrm{CH}_{2}-5$ piperidine), 3.731 (bs, $4 \mathrm{H}, \mathrm{CH}_{2}-2$ and $\mathrm{CH}_{2}-6$ piperidine), $7.455(\mathrm{t}, 1 \mathrm{H}, \mathrm{J} 7.3, \mathrm{CH}-4 \mathrm{Ph})$, 7.537 (t, $2 \mathrm{H}, \mathrm{J}$ 7.4, $\mathrm{CH}-3$ and $\mathrm{CH}-5 \mathrm{Ph}$ ), 7.600 (ddd, $1 \mathrm{H}, \mathrm{J}$ 1.1, 6.9, 8.2, CH-8 Ar), 7.729 (ddd, 1H, J 1.2, 6.8, 8.2, CH-7 Ar), 7.937 (s, 1H, CH-3 $\mathrm{Ar}), 7.974(\mathrm{~d}, 2 \mathrm{H}, \mathrm{J} 7.5, \mathrm{CH}-2$ and $\mathrm{CH}-6 \mathrm{Ph}), 8.432$ (d, $1 \mathrm{H}, \mathrm{J} 8.3, \mathrm{CH}-9$ $\mathrm{Ar}), 8.889$ (d, 1H, J 8.4, CH-6 Ar), 11.789 (bs, $1 \mathrm{H}, \mathrm{OH}) ;{ }^{13} \mathrm{C}$ NMR $24.55\left(\mathrm{CH}_{2}-4\right.$ piperidine $), 26.08\left(\mathrm{CH}_{2}-3\right.$ and $\mathrm{CH}_{2}-5$ piperidine $)$, $47.23\left(\mathrm{CH}_{2}-2\right.$ and $\mathrm{CH}_{2}-6$ piperidine), 112.14 ( $\left.\mathrm{CH}-3 \mathrm{Ar}\right), 116.15$ ( $\left.C_{\text {quat }}-2 \mathrm{Ar}\right), 122.59$ ( $\mathrm{CH}-2$ and $\left.\mathrm{CH}-6 \mathrm{Ph}\right), 123.01(\mathrm{CH}-6 \mathrm{Ar}), 123.78$ (CH-9 Ar), 125.76 ( $C_{\text {quat }}-10 \mathrm{Ar}$ ), 126.22 ( $\left.\mathrm{CH}-8 \mathrm{Ar}\right), 129.11$ (CH-3 and CH-5 Ph), 129.51 (CH-7 Ar), 130.28 (CH-4 Ph), 133.99 (C $\left.C_{\text {quat }}-5 \mathrm{Ar}\right)$, 138.84 ( $\left.C_{\text {quat }}-4 \mathrm{Ar}\right), 152.78$ ( $\left.C_{\text {quat }}-1 \mathrm{Ph}\right), 162.10$ ( $\left.C_{\text {quat }}-1 \mathrm{Ar}\right), 171.58$ $(C=0)$; COSY cross peaks $1.726 / 3.731,7.455 / 7.537,7.537 / 7.974$, 7.600/7.729, 7.600/8.432, 7.729/8.889; NOESY cross peaks $1.726 /$ $3.731,1.726 / 7.937,3.731 / 7.937,7.455 / 7.537,7.537 / 7.974,7.600 /$ $7.729,7.600 / 8.432,7.729 / 8.889$; HSQC cross peaks $1.726 / 24.55$, 1.726/26.08, 3.731/47.23, 7.455/130.28, 7.537/129.11, 7.600/126.22, $7.729 / 129.51,7.937 / 112.14, \quad 7.974 / 122.59,8.432 / 123.78, \quad 8.889 /$ 123.01; HMBC cross peaks 1.726/24.55, 1.726/47.23 (weak), 3.731/ $24.55,3.731 / 26.08,3.731 / 47.23$ (weak), 3.731/171.58, 7.455/ 122.59, 7.537/122.59 (weak), 7.537/129.11, 7.537/152.78, 7.600/ 123.01, 7.600/125.76, 7.729/123.78, 7.729/133.99, 7.937/133.99, 7.937/138.84 (weak), 7.937/162.10 (weak), 7.937/171.58, 7.974/ 122.59, 7.974/130.28, 7.974/152.78 (weak), 8.432/129.51, 8.432/ 133.99, 8.889/125.76, 8.889/138.84 (weak); ${ }^{1} \mathrm{H}$ NMR $\left(\mathrm{CD}_{3} \mathrm{COCD}_{3}\right)$ 1.705 (bm, $4 \mathrm{H}, \mathrm{CH}_{2}-3$ and $\mathrm{CH}_{2}-5$ piperidine), 1.752 (bm, $2 \mathrm{H}, \mathrm{CH}_{2}-4$ piperidine), 3.719 (bs, $4 \mathrm{H}, \mathrm{CH}_{2}-2$ and $\mathrm{CH}_{2}-6$ piperidine), 7.477 (bs, $1 \mathrm{H}, \mathrm{CH}-4 \mathrm{Ph}$ ), 7.588 (t, 2H, J 7.6, CH-3 and $\mathrm{CH}-5 \mathrm{Ph}), 7.669$ (t, $1 \mathrm{H}$, J 7.6, $\mathrm{CH}-8 \mathrm{Ar}$ ), 7.811 (ddd, $1 \mathrm{H}, \mathrm{J} 1.2,6.9,8.2, \mathrm{CH}-7 \mathrm{Ar}$ ), 7.967 (bs, $2 \mathrm{H}, \mathrm{CH}-2$ and $\mathrm{CH}-6 \mathrm{Ph}), 8.028(\mathrm{~s}, 1 \mathrm{H}, \mathrm{CH}-3 \mathrm{Ar}), 8.374(\mathrm{~d}, 1 \mathrm{H}$, J 7.9, CH-9 Ar), 8.912 (bs, 1H, CH-6 Ar); m/z (EI) 359 (100, M $\left.{ }^{+}\right), 289$ (5), 274 (77), 254 (36), 246 (28), 218 (8), 197 (26), 169 (82), 141 (29), 113 (27), 105 (12\%); HRMS (EI): $\mathrm{M}^{+}$, found 359.1628. $\mathrm{C}_{22} \mathrm{H}_{21} \mathrm{~N}_{3} \mathrm{O}_{2}$ requires 359.1634 .

4.1.4.2. (1-Hydroxy-4-(phenyldiazenyl)naphthalen-2-yl)(morpholin$1-y l)$ methanone $\mathbf{3 b}$. Starting from crude $\mathbf{6 b} ; 44 \%$ overall yield; $R_{\mathrm{f}}$ $0.28\left(\mathrm{CH}_{2} \mathrm{Cl}_{2}\right.$ :acetone 95:5); red crystals, m. p. $179-180{ }^{\circ} \mathrm{C} ;{ }^{1} \mathrm{H}$ NMR $3.712\left(\mathrm{~m}, 4 \mathrm{H}, \mathrm{CH}_{2}-2\right.$ and $\mathrm{CH}_{2}-6$ morpholine), $3.769\left(\mathrm{~m}, 4 \mathrm{H}, \mathrm{CH}_{2}-3\right.$ and $\mathrm{CH}_{2}-5$ morpholine), 7.395 (t, $1 \mathrm{H}, \mathrm{J} 7.3, \mathrm{CH}-4 \mathrm{Ph}$ ), 7.469 (dd, $2 \mathrm{H}$, $\mathrm{J}$ 7.3, 7.8, CH-3 and $\mathrm{CH}-5 \mathrm{Ph}$ ), 7.540 (ddd, $1 \mathrm{H}, \mathrm{J} 1.1,6.8,8.1, \mathrm{CH}-8 \mathrm{Ar}$ ), 7.668 (ddd, $1 \mathrm{H}, \mathrm{J}$ 1.2, 6.9, 8.2, CH-7 Ar), 7.784 (s, 1H, CH-3 Ar), 7.897 (d, 2H, J 7.6, CH-2 and CH-6 Ph), 8.363 (d, 1H, J 8.3, CH-9 Ar), 8.812 
(d, 1H, J 8.2, CH-6 Ar), 11.648 (bs, $1 \mathrm{H}, \mathrm{OH}) ;{ }^{13} \mathrm{C}$ NMR $45.52\left(\mathrm{CH}_{2}-3\right.$ and $\mathrm{CH}_{2}-5$ morpholine), $65.87\left(\mathrm{CH}_{2}-2\right.$ and $\mathrm{CH}_{2}-6$ morpholine), 110.23 ( $\mathrm{CH}-3 \mathrm{Ar}$ ), 113.01 ( $\mathrm{C}_{\text {quat }}-2 \mathrm{Ar}$ ), 121.68 ( $\mathrm{CH}-2$ and $\mathrm{CH}-6 \mathrm{Ph}$ ), 122.08 (CH-6 Ar), 122.80 ( $\mathrm{CH}-9 \mathrm{Ar}), 124.83$ ( $C_{\text {quat }}-10 \mathrm{Ar}$ ), 125.44 ( $\mathrm{CH}-8 \mathrm{Ar}), 128.15$ (CH-3 and $\mathrm{CH}-5 \mathrm{Ph}), 128.76$ (CH-7 Ar), 129.49 ( $\mathrm{CH}-4 \mathrm{Ph}), 132.86$ ( $\left.C_{\text {quat }}-5 \mathrm{Ar}\right), 138.28$ ( $\left.C_{\text {quat }}-4 \mathrm{Ar}\right), 151.69$ ( $C_{\text {quat }}-1$ $\mathrm{Ph}), 160.89\left(C_{\text {quat }}-1 \mathrm{Ar}\right), 170.73(C=0)$; COSY cross peaks 3.712 / 3.769, 7.395/7.469, 7.469/7.897, 7.540/7.668, 7.540/8.363, 7.668/ 8.812; NOESY cross peaks 3.712/3.769, 3.769/7.784, 7.395/7.469, $7.469 / 7.897,7.540 / 7.668,7.540 / 8.363,7.668 / 8.812$; HSQC cross peaks 3.712/65.87, 3.769/45.52, 7.395/129.49, 7.469/128.15, 7.540/ $125.44,7.668 / 128.76,7.784 / 110.23,7.897 / 121.68,8.363 / 122.80$, 8.812/122.08; HMBC cross peaks 3.712/65.87, 3.769/45.52 (weak), $3.769 / 170.73,7.395 / 121.68,7.469 / 121.68$ (weak), 7.469/128.15, $7.469 / 151.69, \quad 7.540 / 122.08,7.540 / 124.83,7.668 / 122.80,7.668 /$ 132.86, 7.784/122.80 (weak), 7.784/132.86, 7.784/138.28, 7.784/ 160.89 (weak),7.784/170.73, 7.897/121.68, 7.897/129.49, 8.363/ 128.76, 8.363/132.86, 8.812/125.44; ${ }^{1} \mathrm{H}$ NMR $\left(\mathrm{CD}_{3} \mathrm{COCD}_{3}\right) 3.749$ (bm, $4 \mathrm{H}, \mathrm{CH}_{2}-2$ and $\mathrm{CH}_{2}-6$ morpholine), 3.773 (bm, $4 \mathrm{H}, \mathrm{CH}_{2}-3$ and $\mathrm{CH}_{2}-5$ morpholine), 7.437 (bs, $1 \mathrm{H}, \mathrm{CH}-4 \mathrm{Ph}$ ), 7.583 (t, 2H, J 7.6, CH-3 and $\mathrm{CH}-5 \mathrm{Ph}$ ), 7.672 (t, 1H, J 7.6, CH-8 Ar), 7.815 (ddd, 1H, J 1.2, 6.9, 8.2, $\mathrm{CH}-7 \mathrm{Ar}$ ), 7.959 (bs, 2H, $\mathrm{CH}-2$ and $\mathrm{CH}-6 \mathrm{Ph}$ ), 8.027 (s, $1 \mathrm{H}, \mathrm{CH}-3$ Ar), 8.370 (d, 1H, J 7.9, CH-9 Ar), 8.899 (bs, 1H, CH-6 Ar); m/z (EI) 361 $\left(92, \mathrm{M}^{+}\right), 274$ (100), 256 (15), 246 (30), 218 (10), 197 (32), 169 (92), 141 (42), 113 (45), 105 (24\%); HRMS (EI): $\mathrm{M}^{+}$, found 361.1435. $\mathrm{C}_{21} \mathrm{H}_{19} \mathrm{~N}_{3} \mathrm{O}_{3}$ requires 361.1426 .

4.1.4.3. (1-Hydroxy-4-(phenyldiazenyl)naphthalen-2-yl)(4-phenylpi perazine-1-yl)methanone $3 \mathbf{c}$. Starting from crude $\mathbf{6 c} ; 47 \%$ overall yield; $R_{\mathrm{f}} 0.48\left(\mathrm{CH}_{2} \mathrm{Cl}_{2}\right.$ :acetone $\left.95: 5\right)$; red crystals, m. p. $183-183.5^{\circ} \mathrm{C}$; ${ }^{1} \mathrm{H}$ NMR 3.308 (t, 4H, J 5.1, $\mathrm{CH}_{2}-3$ and $\mathrm{CH}_{2}-5$ piperazine), 3.993 (t, $4 \mathrm{H}$, J 5.1, $\mathrm{CH}_{2}-2$ and $\mathrm{CH}_{2}-6$ piperazine), 6.928 (tt, $1 \mathrm{H}, \mathrm{J} \mathrm{0.9,} \mathrm{7.3,} \mathrm{CH}-4$ $\mathrm{N}-\mathrm{Ph}$ ), 6.955 (dd, 2H, J 0.9, 8.7, CH-2 and $\mathrm{CH}-6 \mathrm{~N}-\mathrm{Ph}$ ), 7.304 (dd, $2 \mathrm{H}$, $\mathrm{J}$ 7.3, 8.7, CH-3 and $\mathrm{CH}-5 \mathrm{~N}-\mathrm{Ph}$ ), 7.492 (tt, $1 \mathrm{H}, \mathrm{J} \mathrm{1.3,} \mathrm{7.3,} \mathrm{CH}-4 \mathrm{Ph}$ ), 7.556 (dd, 2H, J 7.3, 8.5, CH-3 and $\mathrm{CH}-5 \mathrm{Ph}$ ), 7.636 (ddd, 1H, J 1.0, 6.8, 8.1, CH-8 Ar), 7.765 (ddd, $1 \mathrm{H}, \mathrm{J} 1.2,6.8,8.2, \mathrm{CH}-7 \mathrm{Ar}$ ), 7.919 (s, 1H, CH-3 Ar), 8.005 (dd, 2H, J 1.3, 8.6, CH-2 and $\mathrm{CH}-6 \mathrm{Ph}$ ), 8.471 (d, 1H, J 8.2, CH-9 $\mathrm{Ar}), 8.941$ (d, 1H, J 8.4, CH-6 Ar), $11.825(\mathrm{~s}, 1 \mathrm{H}, \mathrm{OH}) ;{ }^{13} \mathrm{C}$ NMR 46.01 ( $\mathrm{CH}_{2}-2$ and $\mathrm{CH}_{2}-6$ piperazine), $49.61\left(\mathrm{CH}_{2}-3\right.$ and $\mathrm{CH}_{2}-5$ piperazine), 108.41 ( $C_{\text {quat }}-2 \mathrm{Ar}$ ), 110.93 ( $\left.\mathrm{CH}-3 \mathrm{Ar}\right), 116.66(\mathrm{CH}-2$ and $\mathrm{CH}-6 \mathrm{~N}-\mathrm{Ph})$, $120.70(\mathrm{CH}-4 \mathrm{~N}-\mathrm{Ph}), 123.01(\mathrm{CH}-2$ and $\mathrm{CH}-6 \mathrm{Ph}), 123.15(\mathrm{CH}-6 \mathrm{Ar})$, 123.77 ( $\mathrm{CH}-9 \mathrm{Ar}), 125.70$ ( $C_{\text {quat }}-10 \mathrm{Ar}$ ), $126.44(\mathrm{CH}-8 \mathrm{Ar}), 129.19(\mathrm{CH}-3$ and $\mathrm{CH}-5 \mathrm{Ph}), 129.35(\mathrm{CH}-3$ and $\mathrm{CH}-5 \mathrm{~N}-\mathrm{Ph}), 129.72(\mathrm{CH}-7 \mathrm{Ar})$, 130.78 (CH-4 Ph), 133.86 ( $\left.C_{\text {quat }}-5 \mathrm{Ar}\right), 139.30$ (C $\left.C_{\text {quat }}-4 \mathrm{Ar}\right), 150.75$ $\left(C_{\text {quat }}-1 \mathrm{~N}-\mathrm{Ph}\right), 153.04\left(C_{\text {quat }}-1 \mathrm{Ph}\right), 161.55\left(C_{\text {quat }}-1 \mathrm{Ar}\right), 172.03(C=0)$; COSY cross peaks 3.308/3.993, 6.928/7.304, 6.955/7.304, 7.492/7.556, $7.556 / 8.005,7.636 / 7.765,7.636 / 8.471,7.765 / 8.941$; NOESY cross peaks 3.308/3.993, 3.308/6.955, 3.308/7.919 (weak), 3.993/7.919, 6.928/7.304, 6.955/7.304, 7.492/7.556, 7.556/8.005, 7.636/7.765, $7.636 / 8.471,7.765 / 8.941,8.471 / 11.825$ (weak); HSQC cross peaks 3.308/49.61, 3.993/46.01, 6.928/120.70, 6.955/116.66, 7.304/129.35, 7.492/130.78, 7.556/129.19, 7.636/126.44, 7.765/129.72, 7.919/110.93, $8.005 / 123.01,8.471 / 123.77,8.941 / 123.15$; HMBC cross peaks $3.308 /$ 49.61, 3.308/172.03 (weak), 3.993/49.61, 3.993/172.03, 6.928/116.66, $6.928 / 129.35$ (weak), 6.955/116.66, 6.955/120.70, 6.955/150.75 (weak), 7.304/116.66 (weak), 7.304/129.35, 7.304/150.75, 7.492/ 123.01, 7.556/123.01 (weak), 7.556/129.19, 7.556/153.04, 7.636/ 123.15, 7.636/125.70, 7.765/123.77, 7.765/133.86, 7.919/133.86, 7.919/ $139.30,7.919 / 161.55, \quad 7.919 / 172.03, \quad 8.005 / 123.01,8.005 / 129.19$, 8.005/153.04 (weak), 8.471/129.72, 8.471/133.86, 8.471/161.55, $8.941 / 125.70,8.941 / 126.44,8.941 / 139.30,11.825 / 108.41,11.825 /$ 125.70, 11.825/161.55; ${ }^{1} \mathrm{H}$ NMR $\left(\mathrm{CD}_{3} \mathrm{COCD}_{3}\right) 3.351$ (bt, $4 \mathrm{H}, \mathrm{CH}_{2}-3$ and $\mathrm{CH}_{2}-5$ piperazine), 3.953 (bs, $4 \mathrm{H}, \mathrm{CH}_{2}-2$ and $\mathrm{CH}_{2}-6$ piperazine), 6.862 (t, 1H, J 7.3, CH-4 N-Ph), 7.037 (dd, 2H, J 0.9, 8.4, CH-2 and $\mathrm{CH}-6$ $\mathrm{N}-\mathrm{Ph}$ ), 7.273 (dd, 2H, J 7.4, 8.4, CH-3 and $\mathrm{CH}-5 \mathrm{~N}-\mathrm{Ph}$ ), 7.485 (bs, $1 \mathrm{H}$,
$\mathrm{CH}-4 \mathrm{Ph}$ ), 7.598 (t, 2H, J 7.4, CH-3 and $\mathrm{CH}-5 \mathrm{Ph}$ ), 7.696 (t, 1H, J 7.4, CH-8 Ar), 7.841 (ddd, $1 \mathrm{H}, \mathrm{J} 1.0,7.3,8.3, \mathrm{CH}-7 \mathrm{Ar}$ ), 7.984 (bs, 2H, CH-2 and $\mathrm{CH}-$ $6 \mathrm{Ph}$ ), 8.103 (s, 1H, CH-3 Ar), 8.401 (d, 1H, J 7.7, CH-9 Ar), 8.932 (bs, 1H, CH-6 Ar); m/z (EI) $436\left(100, \mathrm{M}^{+}\right), 331$ (10), 274 (39), 246 (15), 218 (9), 197 (14), 169 (44), 141 (28), 113 (31), 105 (29\%); HRMS (EI): $\mathbf{M}^{+}$, found 436.1902. $\mathrm{C}_{27} \mathrm{H}_{24} \mathrm{~N}_{4} \mathrm{O}_{2}$ requires 436.1899 .

4.1.4.4. 4-Phenylazo-2-acetyl-1-naphthol 4. Starting from 9; $82 \%$ yield; $R_{\mathrm{f}} 0.36$ (hexane: $\mathrm{CH}_{2} \mathrm{Cl}_{2} 1: 1$ ); orange-red crystals; m. p. 145.5-146 ${ }^{\circ} \mathrm{C}$ (lit. $136{ }^{\circ} \mathrm{C}$ [28], $143{ }^{\circ} \mathrm{C}$ [29]); ${ }^{1} \mathrm{H}$ NMR 2.812 (s, 3H, $\mathrm{CH}_{3}$ ), 7.535 (tt, $1 \mathrm{H}, \mathrm{J} 1.9,7.3, \mathrm{CH}-4^{\prime} \mathrm{Ph}$ ), 7.598 (ddt, $2 \mathrm{H}, \mathrm{J}$ 1.3, 1.7, 7.3, 7.8, $\mathrm{CH}-3^{\prime}$ and $\mathrm{CH}-5^{\prime} \mathrm{Ph}$ ), 7.666 (ddd, $1 \mathrm{H}, \mathrm{J} 1.2,6.9,8.1, \mathrm{CH}-8 \mathrm{Ar}$ ), 7.825 (ddd, $1 \mathrm{H}, \mathrm{J}$ 1.4, 6.9, 8.2, CH-7 Ar), 8.050 (ddd, 2H, J 1.3, 1.7, 7.8, $\mathrm{CH}-2^{\prime}$ and $\left.\mathrm{CH}-6^{\prime} \mathrm{Ph}\right), 8.153(\mathrm{~s}, 1 \mathrm{H}, \mathrm{CH}-3 \mathrm{Ar}), 8.548(\mathrm{~d}, 1 \mathrm{H}, \mathrm{J} 8.2$, CH-9 Ar), 8.922 (d, 1H, J 8.4, CH-6 Ar), 14.287 (s, 1H, OH) ${ }^{13}{ }^{1}$ NMR $27.11\left(\mathrm{CH}_{3}\right), 111.37(\mathrm{CH}-3 \mathrm{Ar}), 112.59\left(\mathrm{C}_{\text {quat }}-2\right), 123.01\left(\mathrm{CH}-2^{\prime}\right.$ and CH-6' Ph), 123.32 (CH-6 Ar), 124.54 (CH-9 Ar), 125.46 ( $\left.C_{\text {quat }}{ }^{-10}\right)$, 126.61 ( $\mathrm{CH}-8 \mathrm{Ar}$ ), 129.20 ( $\mathrm{CH}-3^{\prime}$ and $\left.\mathrm{CH}-5^{\prime} \mathrm{Ph}\right), 130.86\left(\mathrm{CH}-4^{\prime} \mathrm{Ph}\right)$, 131.00 (CH-7 Ar), 135.46 ( $\left.C_{\text {quat }}-5\right), 139.78$ ( $\left.C_{\text {quat }}-4\right), 153.04\left(C_{\text {quat }}-{ }^{\prime}{ }^{\prime}\right.$ $\mathrm{Ph}), 164.72$ ( $\left.C_{\text {quat }}-1\right), 205.49(C=0)$; COSY cross peaks 7. 535/ $7.598,7.598 / 8.050,7.666 / 7.825,7.666 / 8.548$; NOESY cross peaks 2.812/8.153, 2.812/14.287 (weak), 7.535/7.598, 7.598/8.050, 7.666/ 7.825, 7.666/8.548, 7.825/8.922, 8.548/14.287; HSQC cross peaks $2.812 / 27.11,7.535 / 130.86,7.598 / 129.20,7.666 / 126.61,7.825 /$ 131.00, 8.050/123.01, 8.153/111.37, 8.548/124.54, 8.922/123.32; HMBC cross peaks 2.812/115.59, 2.812/205.49, 7.535/123.01, $7.598 / 129.20,7.598 / 153.04,7.666 / 123.32,7.666 / 125.46,7.825 /$ $124.54,7.825 / 135.46,8.050 / 123.01,8.050 / 130.86,8.050 / 153.04$ (weak), 8.153/135.46, 8.153/139.78, 8.153/164.72, 8.153/205.49, $8.548 / 131.00,8.548 / 135.46,8.548 / 164.72,8.922 / 125.46,8.922 /$ 139.78, 14.287/112.59, 14.287/125.46, 14.287/164.72; ${ }^{1} \mathrm{H}$ NMR $\left(\mathrm{CD}_{3} \mathrm{COCD}_{3}\right) 2.829\left(\mathrm{~s}, 3 \mathrm{H}, \mathrm{CH}_{3}\right), 7.607\left(\mathrm{tt}, 1 \mathrm{H}, \mathrm{J} 1.9,7.2, \mathrm{CH}-4^{\prime} \mathrm{Ph}\right)$, 7.665 (ddt, $2 \mathrm{H}, \mathrm{J} 1.2,1.7,7.3,7.9, \mathrm{CH}-3^{\prime}$ and $\mathrm{CH}-5^{\prime} \mathrm{Ph}$ ), 7.743 (ddd, $1 \mathrm{H}, \mathrm{J}$ 0.9, 6.9, 8.0, CH-8 Ar), 7.906 (ddd, $1 \mathrm{H}, \mathrm{J} 1.2,6.9,8.2, \mathrm{CH}-7 \mathrm{Ar}$ ), 8.072 (ddd, $2 \mathrm{H}, \mathrm{J} \mathrm{1.0,1.9,} \mathrm{7.4,} \mathrm{CH}-2^{\prime}$ and $\mathrm{CH}-6^{\prime} \mathrm{Ph}$ ), $8.253(\mathrm{~s}, 1 \mathrm{H}$, CH-3 Ar), 8.496 (d, 1H, J 8.4, CH-9 Ar), 8.954 (d, 1H, J 8.4, CH-6 Ar), $14.423(\mathrm{~s}, 1 \mathrm{H}, \mathrm{OH})$

\subsection{Quantum chemical calculations}

Ab initio HF/6-31G** calculations were performed by using the Gaussian 09 program suite [30]. The effect of the solvent was described using the Polarizable Continuum Model (PCM) model [31]. The individual tautomeric forms and the keto dimers in gas phase were optimized without restrictions and then were characterized as true minima by vibrational frequency calculations. In acetone environment the dimer-acetone complex was optimized taking the X-ray structure as initial approximation.

The use of the HF method has been justified by a comparative study of various levels of theory in the description of the tautomeric equilibrium in azonaphthols [32,33].

\subsection{UV-Vis spectroscopy}

The absorption spectra were measured on Jasco V-570 UV-VisNIR spectrophotometer equipped with Julabo ED thermostat at constant temperature of $20^{\circ} \mathrm{C}$. Spectral grade solvents were used (Scharlau Multisolvent). Typical concentration range solutions of $10^{-5} \mathrm{~mol} / \mathrm{l}$ were measured.

\subsection{Crystallography}

\subsection{1. (1-Hydroxy-4-(phenyldiazenyl)naphthalen-2-yl)(morpholin- 1-yl)methanone $\mathbf{3 b}$}

The crystal of $\mathbf{3 b}$ was mounted of on a loop and all geometric and intensity data were taken from this crystal. Data collection 
using Mo- $\mathrm{K}_{\alpha}$ radiation $(\lambda=0.71073 \AA$ ) was performed at $150 \mathrm{~K}$ on a STOE IPDS-II diffractometer equipped with an Oxford Cryosystem open flow cryostat [34]. Absorption correction was partially integrated in the data reduction procedure [35]. The structure was solved by SIR 2004 and refined using full-matrix least-squares on $F^{2}$ with the SHELX-97 package [36,37].

Crystal data of: monoclinic, $C 2 / c$ (No. 15), $a=26.521(3) \AA$, $b=8.1089(6) \AA, c=19.766(2) \AA, \beta=111.006(8)^{\circ} . V=3968.3(7) \AA^{3}$, $Z=4, d=1.307 \mathrm{Mg} \mathrm{m}^{-3}$, 5519 reflections collected, 2981 unique, $R 1=0.0857(I>2 \mathrm{~s}(I)), w R 2=0.2056$ (all data).

Compound $\mathbf{3 b}$ crystallizes in the monoclinic space group $\mathrm{C} 2 / \mathrm{c}$ $\left(\mathrm{N}^{\circ} 15\right)$ with two molecules of $\mathbf{3 b}$ and one acetone molecule per asymmetric unit (Fig. 5). The backbone of the compound consists in a phenyl ring attached to a functionalized naphthalene by a diazenyl function with $\mathrm{C} 1-\mathrm{N} 1, \mathrm{C} 7-\mathrm{N} 2, \mathrm{~N} 1-\mathrm{N} 2$ bond lengths of respectively 1.41(1) $\AA, 1.35(1) \AA$ and 1.34(1) $\AA$ and the torsion angle $\mathrm{C} 1-\mathrm{N} 1-\mathrm{N} 2-\mathrm{C} 7$ of $176.9(9)^{\circ}$. On the naphthalene moiety, C10 is connected to 01 with a bond length of 1.25(1) $\AA$, and C9 is connected to a morpholine by $\mathrm{C} 17$, with $\mathrm{C} 17-\mathrm{O} 2$ and $\mathrm{C} 17-\mathrm{N} 3$ bond lengths of $1.23(2) \AA$ and 1.34(2) respectively. The morpholine part has a chair conformation with a torsion angle $03-\mathrm{C} 20-\mathrm{C} 21-\mathrm{N} 3$ of $56(1)^{\circ}$.

The presence of a delocalized hydrogen atom (N1...H1 bond length is 1.351(9) $\AA$ ) explains the difference in the bond length of $\mathrm{C} 1-\mathrm{N} 1$ and $\mathrm{C} 7-\mathrm{N} 2$, as this hydrogen atom is also connected to O2\#1 (, \#1: 1-x, $y, 0.5-z$ ) (bond length 1.36(1) $\AA$ ) and forms intermolecular hydrogen bonding (Fig. 6). These two molecules are arranged in a "V" shape, in between which the acetone molecule is placed. This arrangement gives an alternation of "two 3b...Acetone... two 3b".

\subsubsection{4-Phenylazo-2-acetyl-1-naphthol 4}

Very small needle like crystals of $\mathbf{4}$ were obtained by slow diffusion of ethyl acetate (containing $4 \mathrm{mg} \mathrm{m}^{-1} 4$ ) in toluene (containing $1 \mathrm{mg} \mathrm{ml}^{-1} 4$ ). The crystals were then subject to macro seeding. Drops of $10 \mu \mathrm{l}$ were mixed with $2.5 \mathrm{ml}$ ethyl acetate and toluene containing $1,2,3,4$ and $5 \mathrm{mg} \mathrm{ml}^{-1}$ of 4 . After a few days, the crystals grew to maximum dimensions $0.8 \times 0.3 \times 0.2 \mathrm{~mm}$ from the $2 \mathrm{mg} \mathrm{ml}^{-1}$ mixture.

The crystal of $\mathbf{4}$ was mounted of on a glass capillary and all geometric and intensity data were taken from this crystal. Data collection using $\mathrm{Cu}-\mathrm{K}_{\alpha}$ radiation $(\lambda=1.5418 \AA$ ) was performed at room temperature on an Oxford diffraction Supernova diffractometer. The structure was solved with SHELXS-97 [37] and refined using full-matrix least-squares on $F^{2}$ with the SHELXL-97 package [37].

Crystal data of 4: monoclinic, $P 2_{1} / \mathrm{c}$ (No. 14), $a=13.0408(6) \AA$, $b=15.6559(9) \AA, c=7.2709(3) \AA, \beta=100.854(4)^{\circ} . V=1457.91(14) \AA^{3}$, $Z=4, d=1.323 \mathrm{Mg} \mathrm{m}^{-3}, 5009$ reflections collected, 2252 unique, $R 1=0.0561(I>2 \mathrm{~s}(I)), w R 2=0.1652$ (all data).

Compound 4 crystallizes in the monoclinic space group $P 2_{1} / \mathrm{C}$ $\left(\mathrm{N}^{\circ}\right.$ 14) with one molecule per asymmetric unit (Fig. 8). The majority of bond lengths and angles are comparable for $\mathbf{3 b}$ and $\mathbf{4}$. (C10-01 1.351(3) $\AA, \mathrm{C} 17=\mathrm{O} 2$ 1.233(3) $\AA$ and torsion angle $\mathrm{C} 1-\mathrm{N} 1-$ $\mathrm{N} 2-\mathrm{C} 7$ of $\left.178.9(3)^{\circ}\right)$. The phenyl and naphthalene rings are nearly planar (r.m.s. of $0.008(2) \AA$ and $0.007(2) \AA$ A respectively). The angle between the mean planes of the rings systems is $23.26(7)^{\circ}$. The molecular structure is stabilized by an intramolecular $\mathrm{O}-\mathrm{H}$... hydrogen bond (D...A of 2.538(4) Å).

The similar values of $\mathrm{C} 1-\mathrm{N} 1$ and $\mathrm{C} 7-\mathrm{N} 2$ bond lengths $(1.432(3)$ and $1.428(3) \AA)$ and the "reduced" $\mathrm{N}=\mathrm{N}$ one $(\mathrm{N} 1-\mathrm{N} 2$ of $1.242(3) \AA)$ do not suggest the presence of a delocalized hydrogen atom near the diazenyl function in 4. Thus not typical intermolecular hydrogen bonding interaction could be observed in the crystal structure of 4 .

\section{Acknowledgments}

The generous financial support by The Bulgarian Science Fund, projects TK-X-1716 (synthesis and spectral studies), UNA-17/2005 (NMR spectrometer), RNF01/0110 (quantum-chemical calculations) and DRNF-02/1 (crystallography), is gratefully acknowledged. We also thank Dr. Nikolay Vassilev from Institute of Organic Chemistry of Bulgarian Academy of Sciences for carrying out the low temperature NMR experiments.

\section{References}

[1] Czarnik AW. Desperately seeking sensors. Chem Biol 1995;2:423-8.

[2] Prodi L, Bolletta F, Montalti M, Zaccheroni N. Luminescent chemosensors for transition metal ions. Coord Chem Rev 2000;205:59-83.

[3] Bren VA. Fluorescent and photochromic chemosensors. Russ Chem Rev 2001; 70:1017-36

[4] Eggins BR. Chemical sensors and biosensors. Chichester, UK: John Wiley; 2002.

[5] Rurack K, Resch-Genger U. Rigidization, preorientation and electronic decoupling - the 'magic triangle' for the design of highly efficient fluorescent sensors and switches. Chem Soc Rev 2002;31:116-27.

[6] Gokel GW, Leevy WM, Weber ME. Crown ethers: sensors for ions and molecular scaffolds for materials and biological models. Chem Rev 2004;104: 2723-50.

[7] Orellana G, Moreno-Bondi MC. Frontiers in chemical sensors: novel principles and techniques. Berlin, Heidelberg, New York, NY: Springer-Verlag; 2005.

[8] Callan JF, De Silva AP, Magri DC. Luminescent sensors and switches in the early 21st century. Tetrahedron 2005;61:8551-88.

[9] Que EL, Domaille DW, Chang CJ. Metals in neurobiology: probing their chemistry and biology with molecular imaging. Chem Rev 2008;108: 1517-49.

[10] De Vries H, Wiersma D-A. Photophysical and photochemical molecular hole burning theory. J Chem Phys 1980;72:1851-63.

[11] Wehrle B, Limbach H-H, Zimmermann $\mathrm{H}$. Variable temperature $* * 1 * * 5 \mathrm{~N}$ CPMAS NMR studies of dye tautomerism in crystalline and amorphous environments. Ber Bunsen-Ges Phys Chem Chem Phys 1987;91: 941-50.

[12] Lyčka A. Multinuclear NMR of azo dyestuffs. Ann Rep NMR Spectr 1993;26: 247-81.

[13] De Silva AP, Fox DB, Moody TS, Weir SM. The development of molecular fluorescent switches. Trends Biotechnol 2001;19:29-34.

[14] Wu K-C, Ahmed MO, Chen C-Y, Huang G-W, Hon Y-S, Chou P-T. 8- $(1,4,7,10$ Tetraoxa-13-azacyclopentadec-13-ylmethyl)quinolin-7-ol: synthesis and application as a highly sensitive metal cation probe. Chem Commun; 2003:890-1.

[15] Kwon JY, Jang YJ, Lee YJ, Kim KM, Seo MS, Nam W, et al. A highly selective fluorescent chemosensor for $\mathrm{Pb}^{2+}$. J Am Chem Soc 2005;127:10107-11.

[16] Ojida A, Takashima I, Kohira T, Nonaka H, Hamachi I. Turn-on fluorescence sensing of nucleoside polyphosphates using a xanthene-based $\mathrm{Zn}$ (II) complex chemosensor. J Am Chem Soc 2008;130:12095-101.

[17] Nedeltcheva D, Antonov L, Lyčka A, Damyanova B, Popov S. Chemometric models for quantitative analysis of tautomeric Schiff bases and azo dyes. Curr Org Chem 2009;13:217-39.

[18] Antonov L, Deneva V, Simeonov S, Kurteva V, Nedeltcheva D, Wirz J. Exploiting tautomerism for switching and signaling. Angew Chem Int Ed 2009;48:7875-8.

[19] Antonov LM, Kurteva VB, Simeonov SP, Deneva VV, Crochet A, Fromm K. Tautocrowns: a concept for a sensing molecule with an active side-arm. Tetrahedron 2010;66:4292-7.

[20] Van Zandt MC, Sibley EO, McCann EE, Combs KJ, Flam B, Sawick DR, et al. Design and synthesis of highly potent and selective (2-arylcarbamoyl-phenoxy)-acetic acid inhibitors of aldose reductase for treatment of chronic diabetic complications. Bioorg Med Chem 2004;12:5661-75.

[21] Antonov L, Fabian WMF, Taylor PJ. Tautomerism in some aromatic Schiff bases and related azo compounds: an LSER study. J Phys Org Chem 2005;18: 1169-75.

[22] Nedeltcheva D, Kurteva V, Antonov L. Gas phase study of molecular switches based on tautomeric proton transfer. Eur J Mass Spectrom 2011; 17:47-56.

[23] Lycka A, Machacek V. ${ }^{13} \mathrm{C}$ and ${ }^{15} \mathrm{~N}-\mathrm{NMR}$ studies of the azo-hydrazone tautomerism of some azo dyes. Dyes Pigm 1986;7:171-85.

[24] Marek R, Lycka A. ${ }^{15} \mathrm{~N}$ NMR spectroscopy in structural analysis. Curr Org Chem 2002;6:35-66

[25] Nedeltcheva D, Kurteva V, Damyanova B, Popov S. Gas-phase tautomerism in 1-phenylazonaphthalene-4-ol: verification of the responses of individual tautomers. Rapid Commun Mass Spectrom 2009;23:1727-34.

[26] The crystallographic data for the products of $\mathbf{3 b}$ and $\mathbf{4}$ were deposited at the Cambridge Crystallographic Data Centre and allocated the deposition numbers CCDC 809928 and CCDC 818645, respectively. Copies of the data can 
be obtained, free of charge, on application to CCDC, 12 Union Road, Cambridge CB2 1EZ, UK; Tel.: +44 1223 762910; fax: +44 1223 336033; e-mail: deposit@ ccdc.cam.ac.uk; http://www.ccdc.cam.ac.uk/deposit.

[27] Gilli P, Pretto L, Bertolasi V, Gilli G. Predicting hydrogen-bond strengths from acid-base molecular properties. The $\mathrm{p} K_{\mathrm{a}}$ slide rule: toward the solution of a long-lasting problem. Acc Chem Res 2009;42:33-44.

[28] Rege AV, Airan JW, Shah SV. Action of $\mathrm{SO}_{2} \mathrm{Cl}_{2}$ and diazonium benzene chloride on some aromatic thio ethers. J Univ Bombay, Sci Phys Sci Math Biol Sci Med 1943;11A(Pt. 5):83-6.

[29] Anand N, Patel DM, Venkataraman K. Azoic dyes. IX. The behavior of 2-benzoylacetyl-1-naphthol towards diazonium salts. Proc - Indian Acad Sciences Sect A 1948;28A:545-55.

[30] Frisch MJ, Trucks GW, Schlegel HB, Scuseria GE, Robb MA, Cheeseman JR, et al. Gaussian 09, revision A.02. Wallingford CT: Gaussian Inc.; 2009.

[31] Tomasi J, Mennucci B, Cammi R. Quantum mechanical continuum solvation models. Chem Rev 2005;105:2999-3094.
[32] Antonov L, Kurteva V, Crochet A, Mirolo L, Fromm KM, Angelova S. Tautomerism in 1-phenylazo-4-naphthols: experimental results vs quantum-chemical predictions. Dyes Pigm 2012;92(1):714-23.

[33] Antonov L, Kawauchi S, Satoh M, Komiyma J. Theoretical investigations on the tautomerism of 1-phenylazo-4-naphthol and its isomers. Dyes Pigm 1998;38: 157-64.

[34] Cosier J, Glazer AM. A nitrogen-gas-stream cryostat for general X-ray diffraction studies. J Appl Crystallogr 1986;19:105-7.

[35] Blanc E, Schwarzenbach D, Flack HD. The evaluation of transmission factors and their first derivatives with respect to crystal shape parameters. J Appl Crystallogr 1991;24:1035-41.

[36] Burla MC, Caliandro R, Camalli M, Carrozzini B, Cascarano GL, De Caro L, et al. SIR2004: an improved tool for crystal structure determination and refinement. J Appl Crystallogr 2005;38:381-8.

[37] Sheldrick GM. SHELX-97, program for crystal structure refinement. University of Göttingen; 1997. 